\title{
Sustainable luxury: current status and perspectives for future research
}

\author{
Jennifer Kunz ${ }^{1} \cdot$ Stephanie May $^{2} \cdot$ Holger J. Schmidt ${ }^{2}$
}

Received: 30 January 2019/Accepted: 9 March 2020/Published online: 25 March 2020

(C) The Author(s) 2020

\begin{abstract}
Over the past decades, the luxury sector has been constantly growing; consequently, luxury products have attracted the interest of many scholars. Nevertheless, only recently research has been started to investigate possible relations between luxury and activities in terms of corporate social responsibility (CSR) and sustainability. This development was overdue: as luxury products often act as industry models, a shift towards sustainable luxury can pave the way for more sustainable mass products on a broad scope as well. Thus, a profound understanding of the mechanisms behind the successful combination of luxury and sustainability can provide insights for both enhancing individual firm success and achieving a shift towards more sustainable products, which is desirable from a societal perspective. To foster this research stream, the present paper provides a systematic literature review on luxury and sustainability in a broader sense, which, based on an inductive approach, identifies the various areas covered by existing research. This allows critical reflection of what is still missing in the ongoing discussions and shows where priorities within research have been set. We identify several major blind spots within extant research and discuss possible further research paths to close them.
\end{abstract}

Jennifer Kunz

jennifer.kunz@wiwi.uni-augsburg.de

Stephanie May

may@hs-koblenz.de

Holger J. Schmidt

hjschmidt@hs-koblenz.de

1 Chair of Controlling, Faculty of Business and Economics, Universität Augsburg,

Universitätsstraße 16, 86159 Augsburg, Germany

2 Faculty of Business and Management, Hochschule Koblenz, University of Applied Sciences, Konrad-Zuse-Straße 1, 56075 Koblenz, Germany 
Keywords Luxury $\cdot$ Sustainability $\cdot$ CSR $\cdot$ Sustainable luxury $\cdot$ Systematic literature review

\section{Introduction}

Challenges, like climate change, declining natural diversity, scarce water and food supply, and social imbalances, have prompted scholars to concentrate more attention on corporate social responsibility (CSR) and sustainable activities. To structure and foster this fast-evolving research field, several published literature reviews have dealt with topics as diverse as the link between corporate social and sustainable engagement and financial performance (Margolis and Walsh 2003; Orlitzky et al. 2003; Peloza 2009), the micro-foundations of this engagement (Gond et al. 2017), the operationalisation and measurement of CSR (Waddock 2004; Wood 2010), the different organisational levels of CSR (Aguinis and Clavas 2012), and research on corporate social and sustainable engagement in particular disciplines (Brammer et al. 2011).

After mainly focusing on commodity products, in recent years, scholars started to investigate CSR and sustainability in the luxury sector, and several prevailing books have sought to link theory and practice in this field (e.g., Amatulli et al. 2017a; Gardetti 2017). This development has been partly fuelled by growing public interest in issues like CSR and sustainability, as problems like climate change are given public focus by media and science (Haunschild et al. 2019). Thus, luxury producers are facing pressure to make their business processes more sustainable ( $\mathrm{Li}$ and Leonas 2019). Moreover, due to fast-growing economies like China, luxury is also a growing sector, and this growing demand means the luxury industry is facing a scarcity of resources, thereby driving the need for the conservation of these resources (Kale and Öztürk 2016; Depeyre et al. 2018). Finally, in many industries luxury brands and products have a leading position and often act as industry models (e.g., Choi 2014). Companies that operate in mass markets copy luxury brands' innovations, thereby influencing societal trends on a broad scale. Thus, scholars have defined the luxury sector's important role in the process of changing production processes and motivating consumers to change their consumption patterns towards a more sustainable way of living, which will be needed to overcome the challenges identified herein (Joy et al. 2012).

To keep track of this growing research interest in sustainable luxury, Athwal et al. (2019) recently published the first literature review considering sustainable luxury marketing. By structuring the existing literature within this field along with (1) consumer concerns and practices, (2) organisational concerns and practices, and (3) international and cross-cultural issues, they provided valuable insights for theory and practice. However, their literature review only considered the marketing perceptive on sustainable luxury.

Sustainable luxury affects whole supply chains and goes beyond the production of luxury products, making the incorporation of the exploitation of raw materials like gold necessary to fully understand its idiosyncrasy compared to sustainable commodity goods. Thus, the investigation of the link between luxury and 
$\mathrm{CSR} /$ sustainability requires a joint effort of scholars from different disciplines, like marketing, production, supply chain management, engineering, and business ethics. Research efforts across such various disciplines offer the possibility of broad insights; however, as stressed by several authors with respect to other research fields linked to CSR (Aguinis and Glavas 2012; 2013; Gond et al. 2017), it also contains the "risk of fragmentation and biased allocation of research effort" (Gond et al. 2017 , p. 225). Such a fragmentation is detrimental to the development of the mentioned deeper understanding. To counter this fragmentation, the present paper strives to complement the attempt by Athwal et al. (2019) to provide an overview of the extent literature by broadening the perspective to all aspects of sustainable luxury, including beyond the marketing sphere. Focusing on peer-reviewed articles across all relevant disciplines, we identified 113 relevant papers-more than twice as many as Athwal et al. (2019). In addition, as the research on sustainable luxury is a fast-growing field, we incorporated the latest papers from 2019, a total of 15, which were not considered by Athwal et al. (2019).

We identified three broad research streams. First, several scholars focus on sustainable luxury products and brands as such and particularly investigate issues around their harm, supply chain, and communication. The possibility of seeing sustainability as a path to introduce innovations into luxury brands and products, the additional values provided by sustainability for luxury brands and products, and the perception of green products as luxury are also covered, but by fewer scholars. Second, several papers cover questions related to CSR and sustainable activities of luxury producers as such. On the one hand, they analyse the effect of these activities on consumer behaviour. On the other hand, they discuss best practice examples for such activities. Third, another part of the literature deals with stakeholders. A large part of this research focuses on consumers and the effect of consumer characteristics on the purchase of sustainable luxury, consumers' perceived compatibility of luxury and sustainability, and the paradox of consumerism. The few remaining papers within this category discuss issues related to managers and staff within the luxury industry and to regulators and researchers. Overall, research on sustainable luxury is a fast-growing field, which has already overcome the state of mere stocktaking and which, by spanning across many disciplines, provides rich evidence for theory and practice. However, the review also indicates that literature has thus far rather scarcely applied existing theory to put the provided evidence onto a theoretical ground. Based on these results, we provide several paths for future research.

The remaining paper is structured as follows. Section 2 provides an overview of the key concepts discussed in this article. Section 3 describes the method applied to perform the systematic literature review. The results of the review are presented in Sect. 4 and discussed in Sect. 5.

\section{Sustainability, CSR, and luxury}

Although the term sustainable luxury has been around for more than a decade (Bendell and Kleanthous 2007), sustainability and CSR on the one hand and luxury on the other hand are still perceived as rather conflicting ideas (Joy et al. 2012; 
Kapferer and Michaut-Denizeau 2014). Moreover, each of these terms still lacks a clear and precise definition, which makes it difficult to capture their core aspects.

Since the first mention of the term sustainability in 1713 and the well-known formulation in the Brundlandt report in 1987, many authors within different disciplines have devoted considerable research effort to further clarify this construct (e.g., Glavič and Lukman 2007; Kajikawa 2008; Dresner 2008; Swanson and Zhang 2012), yet sustainability is still understood and interpreted in different ways and lacks a commonly accepted clear definition defining its boundaries (Partridge 2011). Terms like ethical, green, eco, organic, and responsible are also associated with it.

Corporate social responsibility (CSR) is a company's commitment to strive for profitability whilst acting as a good citizen (Freeman and Velamuri 2006), improving the liveability of its employees, their families, the local community, and society as a whole (WBSCD 2000). CSR replaces mere compliance with regulatory standards (Kerr et al. 2009). Although the terms sustainability and CSR are often used synonymously (Gatti and Seele 2014), Carroll and Shabana (2010, p. 86) argue that "CSR remains a dominant, if not exclusive term in scientific literature and business practice".

In 1979 Carroll provided the basis for one of the most influential concepts of CSR. According to his understanding, the "social responsibility of business encompasses the economic, legal, ethical, and discretionary expectations that society has of organisations at a given point in time" (Carroll 1979, p. 500). This definition was the basis for the so-called Pyramid of Corporate Social Responsibility (Carroll 1991; 2016; Schwartz and Carroll 2003), whose uniqueness and usefulness were subsequently proven through a series of early empirical studies (Aupperle 1984; Edmondson and Carroll 1999; Pinkston and Carroll 1996).

Overall, research on CSR has grown considerably in different directions over the last decades. Dahlsrud (2008) discussed more than 35 definitions of CSR. Lee (2008) published a review of CSR theories "to trace the conceptual evolutionary path of theories on corporate social responsibility (CSR) and to reflect on the implications of the development" (p. 53). Several extant literature reviews have provided a broad perspective for future discussions, many of them focusing on determinants or drivers, mediators, moderators, and outcomes or reactions towards CSR activities at different organisational levels (e.g., Aguinis and Glavas 2012; Rupp and Mallory 2015; Gond et al. 2017).

In general, luxury products (e.g., fine art, cars, leather goods, high fashion, and jewellery) are related to three core aspects. First, they are related to feelings and sensual experiences (Kapferer 1997). Second, they go beyond the necessary (Berry 1994). Third, their high price is typically not related to their production costs (Nueno and Quelch 1998). Yet, the literature emphasises that one unifying definition of the concept of a luxury product is difficult (Berthon et al. 2009; Lasslop 2005). One major difficulty lies in the fact that the term "luxury product", to which we fundamentally refer to in this review, is a relative concept. It depends on the definition of what is actually necessary (Sombart 1922/1967), and a necessity for the one person or society can mean luxury for another person or another society (Berry 1994). Thus, luxury has always also been a social theme as it is associated with the useful and the useless, the social structures, local culture, aesthetics, as well as the 
distribution of wealth (Kapferer and Bastien 2009). Moreover, luxury depends on the respective epoch, the political-economic environment, and the moral-ethical standpoint of the observer (Berry 1994; Lasslop 2005; Valtin 2005). In addition, culture plays a role as several comparative studies found strong intercultural differences regarding the perception of luxury products (Tidwell and Dubois 1996; Wong and Zaichkowski 1999). Finally, luxury constitutes a model for mass production, and thus, has a strong impact on production and consumption patterns (e.g., Choi 2014).

Despite the various connotations of luxury (see, for example, Bastien and Kapferer 2013 and Kapferer and Bastien 2009), there is consensus amongst scholars that consumers' associations towards luxury products can be described with phrases like good taste, classy, quality, high-priced, eye-catching, uniqueness, scarcity or limited accessibility, aesthetics, history, self-pleasure, and non-necessity (Dubois and Laurent 1994; Dubois and Paternault 1995; Dubois et al. 2001; De Barnier et al. 2006). The social need for prestige and recognition can be considered an important trigger of luxury consumption, although it has become smaller over time (Amaldoss and Jain 2002). The need for uniqueness, conformity, and self-reward also influences buying behaviour (Amaldoss et al. 2002; Tsai 2005), and the emotional and symbolic characteristics of a luxury product could even outweigh the rational and product-specific ideas connected with it (Dubois et al. 2001). To structure the different aspects of relevance in this context, Wiedmann et al. (2007) developed a multidimensional framework of consumers' luxury value perception that also serves as a general basis for the identification of value-based consumer segments. Within their framework, individual, social, financial, and functional dimensions determine the value of luxury products and their consumption.

The shown characteristics of luxury and luxury products are partly compatible with aspects of social and sustainable engagement and partly contradictory to it, which can make sustainable luxury a difficult venture. According to Kapferer and Michaut-Denizeaut (2014), "sustainability silence" is discernible in the luxury industry, even if an awareness of social and ecological issues actually exists.

\section{Method}

To identify the relevant literature, we carried out a systematic literature review (SLR) (Tranfield et al. 2003), which is considered the most appropriate method to survey existing research, analyse the development of a research field, and provide insights about existing research gaps (Fink 2005). We accomplished a three-stage procedure comprising planning, execution, and reporting (Fink 2005; Tranfield et al. 2003). In the planning stage, we defined the explicit aims of the research. First, we strived to summarise the state of the art of research on sustainable luxury, its various manifestations, and its characteristics. Second, based on this summary, we sought to uncover key areas within research and provide insights for new research streams.

To reach this objective, it was important to comprehensibly limit the search criteria and retain the search criteria for each individual search within the various databases. Therefore, we limited ourselves to the following criteria: 
- only articles in peer-reviewed scientific journals, because they can be considered as validated knowledge and are expected to have the highest impact in the research field

- articles written exclusively in English

- articles in the field of business in general

Furthermore, we clearly limited our search period according to the date of publication as 1 January 2000 to 1 June 2019 because, before 2000, almost no publications on the subject existed; moreover, we aimed to focus on more current research. In addition, no book publications or anthologies were considered, nor were any industry reports, conference reports, or articles in non-scientific journals. We selected the document type article in each search mask.

To be considered in the review process, papers had to contain at least one of the nine following terms along with the term luxury: (1) sustainability, (2) sustainable, (3) CSR/corporate social responsibility (same hits on both terms), (4) responsible, (5) responsibility, (6) ethical, (7) green, (8) eco, and (9) organic. The choice of terms clearly shows that research in the field of sustainability encompasses a multitude of terms (e.g., green, eco, or bio) and has a common association. This is driven by, amongst other factors, the fashion industry (Carey and Cervellon 2014), such as fair fashion, and can also be seen in many other industries, e.g., food, where a large number of food labels exist to mark ecological and fair origins or shares. Although the concepts of the terms differ considerably, they are often used synonymously (Carey and Cervellon 2014). Accordingly, we included this wide range of synonyms and interrelated terms in our search of sustainability.

For our search, we used the databases ABI Inform Global, Ebsco Business Source Premier, Ingenta, Science Direct, and Scopus because they expose the most comprehensive number of peer-reviewed journals in the fields of management, organisation, and social science. Apart from Ingenta, all databases were subject to the "peer-reviewed" restriction. Within Ingenta, we manually selected articles that had been peer-reviewed.

The second stage of the SLR process, the execution phase, comprised two steps: data collection and data analysis. The data collection contained the extraction of the publications from the electronic databases. From 11 June 2019 to 19 June 2019, the databases were screened for articles including the combinations of the previously identified terms in the title, keyword, or abstract. Forty-five database searches $(9 \times 5)$ were performed using the identified terms whilst considering the mentioned criteria.

When entering the search terms, we first received a very large number of hits $(>60,000$ ), with the majority of hits coming from the ABI INFORM and Science Direct databases $(>56,000)$. This showed that some terms yielded considerably more results than others (see Table 1 in Appendix). Duplets were still preserved at that time (i.e., journal articles that appeared twice by searching with different keywords or in different databases). We then narrowed down the hits again (roughly), based on viewing just the first 15 result pages of the search (if that many pages were shown), which led to a significantly reduced result of 673 hits (see again Table 1). We quickly realised that, in the further course of the search, the relevance 
of the content decreased significantly until no more relevance was discernible. The following analysis phase included different steps. First, the abstracts of the 673 papers were read, and only those papers relevant to our research aim were considered for the current paper. Duplications were deleted in this phase. After this step, we were able to select 123 articles with relevant content. The extracted material was then named and stored.

Next, we applied a content analysis technique to analyse each article (Hsieh and Shannon 2005). Based on the suggestions of Coviello and Jones (2004), we transferred the extracted data to a descriptive working table to allow for easy comparability and applied the following categories:

- reference data: year of publication, journal, country, and department (university association) of the first author

- context issues: which industry, product, or concept is considered

- content issues: main topics of research

- methodology issues: which type of method (empirical or conceptual) and which particular method (e.g., literature review, case study, survey) are applied

After this further thorough analysis of the selected 123 articles, another 20 articles were eliminated as inappropriate in content, leaving 103 articles. We then checked the references of the identified articles for further peer-reviewed articles matching our criteria. We identified six additional papers, which were also considered in the following analysis. Three articles were added manually as they did not appear in the systematic search, but we discovered them by chance in the course of the research. These three articles also correspond to our criteria.

Based on this methodological procedure, we ultimately identified 112 articles whose time distribution varies since 2000 (see Fig. 1). Academic research interest in sustainable luxury increased in 2010 and gained attention in 2013. Since then, this development has remained stable, with a small drop in 2014 and a stronger decline in 2015 .

The selected articles are presented in a concept matrix (Webster and Watson 2002) in Appendix (Table 2); the matrix depicts the various methodological categories, shows the classification of the papers into empirical and conceptional papers, and provides information on the concrete method applied within each paper. Thus, the matrix reveals the methodological research focus over time on sustainable luxury.

\section{Results}

\subsection{Areas of interest}

The identified papers deal with three major topics. First, many scholars focus on sustainable luxury brands and products. In this context, they consider both hard and soft facts. Harm chain analyses, the discussion of sustainability as a way to introduce innovation into luxury brands and products, and the communication in the context of sustainable luxury pertain to the first area (the hard facts) whilst the 


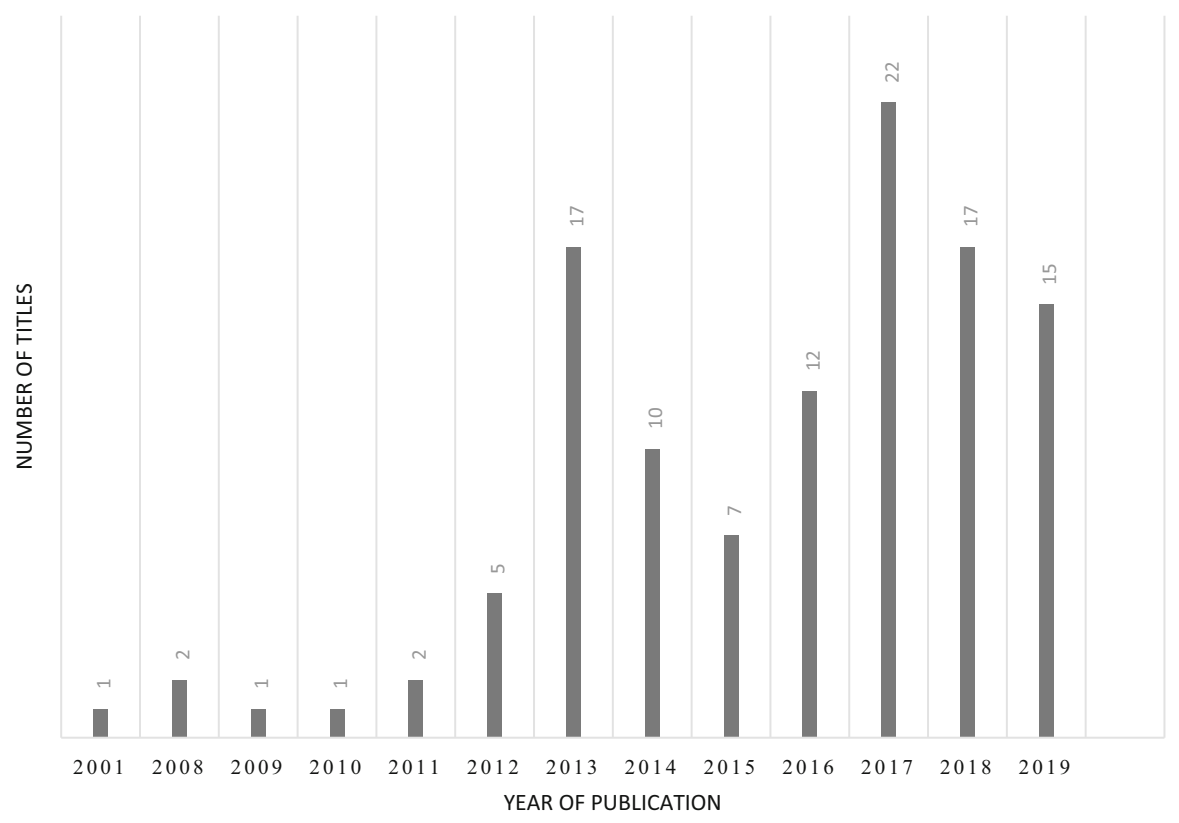

Fig. 1 The allocation of published articles by year

investigation of values linked to sustainable luxury and the perception of ecoproducts as luxury products are topics of a rather soft character. Second, several papers concentrate on CSR and sustainable activities (hereafter, shortened as CSR activities) in the context of luxury. On the one hand, they investigate the effects of these activities on consumers; on the other hand, they discuss best-practice examples of these activities. Third, a large group of scholars concentrate on the impact of stakeholders on the success or failure of sustainable luxury. On the one hand, there are three areas, which focus on customers as the most important group. Within this research, the effect of customer characteristics, the perception of compatibility between luxury and sustainability, and the paradox of consumerism are analysed. On the other hand, managers and staff as well as regulators and researchers are considered. Figure 2 provides an overview regarding this structure. Furthermore, the number of papers within the different areas is indicated via the font size to demonstrate the difference between these areas in terms of scholars' attention.

Twelve sub-categories were identified within the three main areas. Perception of compatibility (21 papers) and effects of customer characteristics (16 papers) have received the most attention so far. Communication (13 papers) and harm and supply chain analysis (11 papers) formed the second strongest group. The remaining topics were values ( 8 papers), best practice ( 8 papers), eco as luxury ( 7 papers), regulators and researchers ( 7 papers), effect of CSR on consumers ( 7 papers), sustainability as innovation (6 papers), paradox of consumerism (4 papers), and managers and staff (4 papers). 


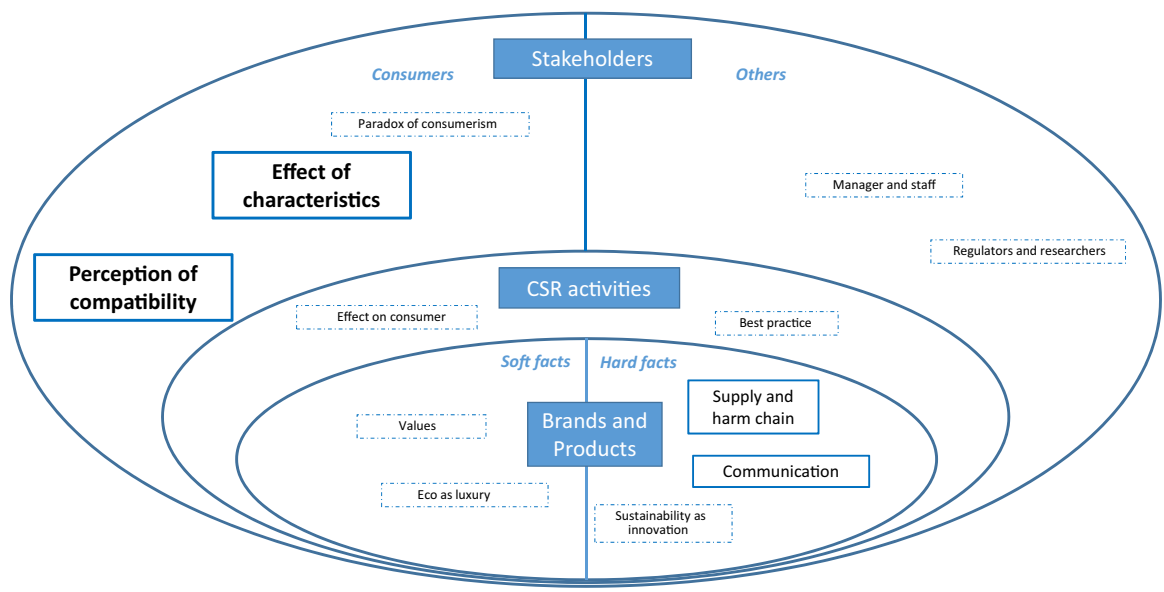

Fig. 2 Identified areas of interest

Sections 4.2, 4.3, and 4.4 are dedicated to the research methods used, the industries, and the applied theories whilst the subsequent sections discuss the three identified major topics and their respective subcategories, with corresponding papers to structure and analyse the existing literature on luxury and sustainability. Table 4 in Appendix provides an overview of the elaborated categories.

\subsection{Research methods}

A large number of the identified papers (112) are empirical (102), of which only eight use both quantitative and qualitative methods (see Table 2 in the Appendix). Thirteen of these papers are both empirical and conceptual. With respect to purely qualitative versus quantitative methods, there is almost an equal split, as 43 papers apply only a quantitative method whereas 38 papers only use a qualitative method. Ten are purely conceptual, whilst several papers that apply an empirical method also strive to advance theory building. For example, Yang et al. (2017) develop a model with respect to value-creation mechanisms and further validate it by applying a case study, and Bendell and Thomas (2013) develop a theory of elegant disruption based on qualitative data.

The identified qualitative approaches are very diverse, ranging from content analysis of websites and communication materials, case studies, focus groups, and visual elicitation techniques to structured interviews. On the quantitative side, experiments and surveys are analysed using methods like ANOVA, conjoint analysis, and structural equation modelling. Consequently, although sustainable luxury has only attracted attention in recent years, this field is fast growing and disposes of a rich methodological tool set.

This methodological richness mirrors the range of different disciplines concentrating on the relation between CSR and luxury, which can be interpreted as an advantage because it shows an openness for different methods and perspectives within this research area. However, as the different methods are applied to a wide 
range of different research objects, the accumulation of knowledge on a particular topic is still not given. More research is needed to cover the same research object with different methods.

\subsection{Industries}

Within the identified research, the fashion and the hospitality industry clearly dominate. Thus, research focuses on two industries, which cause considerable harm to the environment, with the fashion industry being "the second largest cause of pollution worldwide" (Woodside and Fine 2019, p. 111). Cars and jewellery are also considered by several scholars, but to a much lesser extent. The discussed raw materials are related to the fashion industry (leather, fur, and wool). The remaining industries cover areas as diverse as real estate, food, and cruises. An overview of the products and industries examined in the individual papers and the field of investigation can be found in Table 3 in the Appendix. Several scholars do not discuss particular industries, but instead cover the topic from a more general point of view, focusing on sustainable luxury products or brand as such. Other important areas of luxury, like sport boats, $\mathrm{Hi}-\mathrm{Fi}$, or electronics, are not included at all amongst the identified papers. Thus, research has a very strong focus on only a small set of luxury industries. Yet already within this set, the difficulty of clearly defining luxury as opposed to mass products becomes apparent. For example, whilst Ali (2017) focuses on diamonds, Steinhart et al. (2013) classify fancy napkins as a luxury product. Both products differ along several dimensions (e.g., scarcity, difficulty to produce, endurably, absolute price). This broad definition of luxury makes it difficult to compare results of different papers. Therefore, more research is needed to identify the differences and similarities in relation to socially and environmentally sustainable luxury in different industries.

Moreover, several industries are completely ignored by extant research in peerreviewed journals. This includes several industries whose products belong to the extraordinarily high-priced luxury products such as boats or airplanes. It would be interesting to learn more about how consumers of such products differ or are similar regarding their attitudes towards socially responsiveness and ecological sustainability and how effective CSR activities in these industries might differ from other luxury industries.

Finally, the majority of the identified empirical research that uses samples relies more on younger people, higher educated people, and people belonging to the middle or upper class, although there are some exceptions (e.g., Amatulli et al. 2018; Bendell and Thomas 2013; Kapferer and Michaut 2015). This observation points to the need to further broaden the perspective on the relevant participants. Thus far, research has focused primarily on participants from social classes who are able to buy and consume luxury products or services. This is reasonable from a marketing point of view. However, given the considerable consumption of scarce resources by production processes within the luxury industry, their outcomes affect also people who cannot afford to buy these produces. To promote research into the responsibility perspective, members of other classes should also be involved to get a full picture. 


\subsection{Applied theories}

Several of the identified papers apply a thorough theoretical basis. For example, Fifita et al. (2019) apply the theory of social practice, and Gibson and Seibold (2013) base their research on self-determination theory. Overall, mostly theories related to aspects of signalling (e.g., Ivanova et al. 2013; Berger 2017), attitudes (e.g., Beckham and Voyer 2014; Jin et al. 2017; Line and Hanks 2016; Pinto et al. 2019), social identity (e.g., Griskevicius et al. 2010; Shilpa and Madhavaiah 2017; Johnson et al. 2018; Ali et al. 2019; Fifita et al. 2019; Kessous and Valette-Florence 2019; Pinto et al. 2019), and motivation (e.g., Gibson and Seibold 2013; Ali et al. 2019; Peng and Chen 2019) are used. Moreover, scholars apply frameworks related to issues around values stemming from marketing (e.g., Hennigs et al. 2013; Cervellon and Shammas 2013; Mititelu et al. 2014; Pinto et al. 2019). Thus, psychological theories and marketing frameworks prevail whereas theories rooted in business ethics are scarcely applied. Moreover, large parts of the literature do not explicitly discuss the theoretical foundation of the conducted research.

\subsection{Brands and products}

\subsubsection{Communication}

One topic that attracted significant interest is the question of communication. The extant literature questions if luxury producers should communicate their CSR and sustainable activities and, if so, how they should do this and what they should actually communicate with respect to their engagement in CSR and sustainability.

4.5.1.1 What should companies communicate? Overall, the literature provides evidence that appropriate communication of CSR and sustainability activities fosters brand value and consumer acceptance. In the pearl industry, correctly formulated messages about environmental outcomes can have a positive impact on brand value (Nash et al. 2016). Rolling and Sadachar (2018) find that the introduction of sustainability does not change Millennials' impression of luxury; in other words, within this audience, sustainability does not compromise the impression of luxury and can be communicated. Steinhart et al. (2013) find that eco-labels can positively influence the evaluation of both utilitarian products and luxury products; for the latter they help justify their consumption. Moreover, communication that leads to the perception of irresponsibility is detrimental: Bryson et al. (2013) find-albeit not articulated explicitly but implicitly by respondentsthat luxury producers should avoid efforts that lead consumers to perceiving them as acting irresponsibly, as this might become a source of brand hate. However, how luxury producers communicate their CSR and sustainable activities is important, as Platania et al. (2019) demonstrate. They analyse the effect of emotions on the consumption of eco-luxury products and find that marketers should apply strategies to foster a symbolic and ideological change that allows consumers to "recognising themselves in them" (Platania et al. 2019, p. 501). Finally, appropriate 
communication can also depend on further factors, as Sthapit et al. (2017) show. They provide evidence of a rather complex relationship between communicating CSR and brand evaluation dependent on the belief in benevolent company motives. If this belief is low, a high fit between the luxury brand and the type of CSR activity enhances brand evaluation; if the belief is high, this fit is unimportant. Consequently, luxury companies should consider such beliefs before communicating any CSR activities.

4.5.1.2 How should they communicate? Luxury producers have different channels through which to communicate their engagement in CSR. Arrigo (2018) discusses the importance of flagship stores as one vehicle to communicate the engagement of luxury producers in sustainability. They stress that a flagship store as a branded space offers the possibility to "enhance stakeholder awareness about the luxury fashion brand's commitment to sustainable development" (Arrington 2017, p. 175). Ivanova et al. (2013) provide a multisensory signal theory on sustainable luxury and apply it to an eco-fashion brand. In doing so, they broaden the marketing practitioners' perspective on the impact of multisensory signals on consumers and provide insights that successful communication of sustainable luxury has to go beyond the mere visual channel. Poldner et al. (2017) provide evidence that aesthetics can act as a mediator to communicate sustainability by translating "individual creativity into artefacts that embody sustainability messages" (Poldner et al. 2017, p. 1945).

\subsubsection{What do they communicate? Overall, communication of luxury producers} tries to transport the perception of a harmonious togetherness between sustainability and luxury without sacrificing any promises made by luxury, like unlimited indulgence. Thus, sustainability is communicated more to enhance the brand value than to transfer any information with respect to the true impact of these activities. By investigating 43 websites of luxury brands, Wong and Dhanesh (2017a) identify two strategies luxury companies use to address the tension between being elite and being social and sustainable on their websites. Either they communicate a harmonious coexistence between CSR and luxury, or they indicate a convergence of both (i.e., try to synthesise them), which ultimately results in a harmonious merger between both. Wong and Dhanesh (2017b) find that the 43 luxury brand websites investigated communicated discretionary CSR activities driven by altruistic motives congruent to the brand and evoked emotions. Cherapanukorn and Focken (2014) analyse the communication strategies of several Asian luxury hotels to identify their CSR practices. They find that "most hotel groups underline the importance of the environment and society; therefore, it can be concluded that the motivations are less financial but oriented towards sustaining the basis for their operations, i.e. the natural and cultural environment including all stakeholders" (Cherapanukorn and Focken 2014, p. 207). However, many of the communicated activities are normal business practices. Freire and Loussaïef (2018) analyse the advertising strategies of Louis Vuitton and Hermès with respect to the communication of their CSR activities. By applying a semiotic analysis, they find that the use 
of adequate symbols in the advertisements of both companies add to the identity value of their brands and the CSR principles.

\subsubsection{Supply and harm chain}

As luxury is associated with unnecessary consumption reserved for only a small fraction of the population, it has always been the object of controversial discussions (Stewart 1918). Therefore, harm chain analyses of luxury products have been increasingly used within the field of sustainable luxury. A harm chain analysis addresses all stakeholders harmed by a particular business model and those parties who can affect these harming processes (e.g., Polonsky et al. 2003). It is closely linked to the supply chain; therefore, both aspects are discussed here jointly. Within this research field, the identified literature focuses on the jewellery, the fashion industry, and tourism. One topic is related to questions of how sustainability can be achieved within the supply chain. Another research stream discusses the possible impact of particular actors within the supply chain. Finally, the question of what sustainability actually means when considering a whole supply chain also rises.

\subsubsection{How do companies achieve sustainability in the supply chain? Ali (2017)} compares natural and synthetic gemstones to evaluate their respective potential for sustainability and argues for a reasonable mixture between both types as both not only have environmental advantages but also disadvantages. Towers et al. (2013) find less sophisticated processes in a Scottish cashmere garment manufacturer in terms of transparency and auditability of the CSR management process than those processes that can be found in mid-market garment manufacturers and retailers. Thus, in this industry, luxury producers seem to lag behind and have to improve their processes. Wang and Snell (2013) analyse the reasons for labour abuse at Gucci in China and provide a model to prevent such abuse. Carrigan et al. (2013) discuss several harms within the supply chain of luxury fashion and show that luxury fashion brands should invest in more sustainable production to remain successful. However, their analysis also reveals the complexities within this industry to change towards more sustainable activities. Yang et al. (2017) provide insights into value-creation mechanisms along the supply chain of luxury fashion that benefit multiple stakeholders and could help resolve these complexities. Several scholars point to the mentioned complexities within the hospitality industry as well. For example, Ryan and Stewart (2009) investigate the effects of the regeneration of the desert Al Maha as an eco-initiative of a luxury resort offering luxurious accommodation. The regeneration of the desert fauna and flora seems to work, but it is intensive in water use. The authors conclude that "[the] best opportunities for environmental regeneration [lie] in the commercialization of nature rather than altruistic motives-but commercialization can only benefit nature if it conveys value to clients. In this instance, the value is represented by the degree of luxury offered by the resort" (Ryan and Stewart 2009, p. 299). Cowburn et al. (2018) analyse the possible negative effects of resort tourism on coral reefs in the Maldives and identify a need for better waste management and a more environmentally 
friendly development of the infrastructure. Based on a survey de-Miguel-Molina et al. (2014) analyse patterns of sustainability in resorts on Small Island Developing States. From their findings, the authors conclude that the achievement of sustainable targets depends on the willingness to sacrifice activities and services, like water sports. In addition, the more general analysis by Roberts (2019) points to these complexities. The author investigates the impact of luxury on welfare and finds positive impacts by promoting economic growth, innovation, and cultural enrichment as well as improved quality of environmentally sustainable business practices. However, the author also identifies regulation and appropriate taxation as important instruments to curtail excess luxury consumption.

4.5.2.2 What impact do small players have? Carrigan et al. (2017) focus on the impact that small- and medium-sized enterprises (SMEs) in particular have on the harm chain in the fine jewellery industry. They find that SMEs perceive their small size as a disadvantage, as they are not heard in this industry, and they see economic factors as more pressing than the introduction of CSR. Overall, for SMEs it seems difficult to address possible changes within this industry towards CSR.

\subsubsection{What does sustainability mean along the supply chain? Csaba and Skjold} (2018) show the difficulties with respect to deciding what sustainable luxury actually is by discussing the case of fur as a luxury product. In this context, they investigate the supply chain: On the one hand, fur is considered a natural and thus theoretically renewable raw material, but on the other hand there is a high demand for resources during the production process, and this is also ethically very questionable.

\subsubsection{Sustainability as an innovation}

Similar to consumer goods producers, luxury manufacturers are also under continuous pressure to remain competitive and cope with the changing and increasing customer demands. Several scholars consider sustainable luxury to be one way to cope with this pressure.

As argued by Kapferer (2014), the luxury industry has to consider sustainability in order to remain competitive. This necessity is underscored by the analyses of Bendell und Thomas (2013), who argue that entrepreneurs change the luxury industry disruptively by introducing innovative sustainable luxury products. The activities of these entrepreneurs change patterns of consumption, production, or exchange to achieve a positive societal outcome, thereby putting inert incumbents under pressure. This observation can be related to the findings of Nunes et al. (2016), who analyse the reasons why luxury car manufacturers have become more sustainable, which are rooted in the pressure of different stakeholders. In addition, Gardetti and Torres (2013) believe in the disruptive power of entrepreneurs who succeed in combining luxury and sustainability. They further stress the consideration of local heritage and present Ainy Savoirs Des Peuple as an example of an entrepreneurial company that succeeds in integrating the environment, innovation, 
stakeholder management, and economic value and growth potential. To provide another example of such an innovation, Guercini and Ranfagni (2013) analyse the innovation in the supply chain of Italian native wool production related to sustainability. Their research "accompanied the planning stages and creation of a textile and clothing supply chain which is sustainable-luxury based, locally extended and grounded in the use of raw wool produced by indigenous sheep" (Guercini and Ranfagni 2013, p. 81). Lucà (2014) provides yet another example, discussing in a descriptive manner the consequences of changing values and attitudes concerning CSR in the leather industry.

\subsubsection{Value}

One prevailing question within extant literature concerns the values attached to sustainability in the context of luxury. The answer to this question is of particular importance to marketers seeking to position their sustainable luxury products according to customers' value perceptions. Scholars discuss issues related to the conceptualisation and measurement of these values and particular examples of value creation.

4.5.4.1 How can one conceptualise and measure values in the context of sustainable luxury? To foster this positioning, Hennigs et al. (2013) provide a comprehensive framework of luxury sustainability values by discussing financial, functional, individual, and social value as those dimensions through which consumers evaluate the (ethical) performance of luxury brands. Cervellon and Shammas (2013) expand (amongst others) Hennigs et al.'s (2012) luxury value framework, which also underlies Hennigs et al. (2013), by identifying three categories of values of sustainable luxury: socio-cultural values (conspicuousness, belonging, and national identity), ego-centred values (guilt-free pleasures, health and youthfulness, hedonism, durable quality), and eco-centred values (doing good, not doing harm). Moreover, depending on the cultural background, these values are of different importance. In addition to this theoretical model, marketers are interested in the measurement of values attached to sustainability. Consequently, Dogan-Sudas et al. (2019) develop a scale containing four dimensions of consumers' value perceptions of luxury brands in an emerging market. One of these dimensions is normative beliefs covering sustainable environment attributes of luxury products.

4.5.4.2 Which examples exist for concrete value assignment? Hartmann et al. (2016) examine the determinants of consumers' perception of the luxury value of food in Germany. They find that, in addition to traditional values, like financial, functional, individual, and social aspects, sustainability and authenticity also contribute to consumers' perceptions of the luxury value of this product. Hartmann et al. (2017) pick up this discussion and identify different segments of consumers with varying attention to the different dimensions. Keith and Silies (2015) investigate the possibility of upcycling pre- and post-consumer textile waste to create luxury textiles. By presenting several projects, they provide insights into how 
design is important to create the perception of luxury. Moreover, the investigation of Giorgio Armani's Acqua for Life Challenge by Mititelu et al. (2014) shows that the social value attached to luxury brands by cause-related marketing can provide a competitive advantage. Turunen and Leipämaa-Leskinen (2015) focus on the value of second-hand luxury brands, a kind of sustainable consumption of luxury products.

\subsubsection{Eco as luxury}

Within the sample of articles, one topic arose that puts luxury and ecological products into a broader perspective. The articles discuss the possibility to perceive at least some eco-brands and eco-products as luxury. Scholars not only identify similarities but also clear differences between both product types in various industries.

4.5.5.1 What are differences between both product types? Kessous and ValetteFlorence (2019) find that different drivers trigger the purchase of first-hand versus second-hand luxury products. In the case of second-hand luxury products, ecoconscious concerns are also important. DiDonato and Jakubiak (2016) analyse whether eco-friendly products can serve as substitutes for luxury products to signal attributes relevant in a romantic context. They found that participants of their study perceived consumers of eco-friendly products as exhibiting greater warmth, competence, and good partner traits but less physical attractiveness compared to luxury purchasers.

\subsubsection{What are the similarities between both product types? Fifita et al. (2019)} find that South Korean consumers of sustainable organic food follow three consumption practices in particular: investing in long-term wellbeing, expressing sustainability values, and signalling social status. They conclude that these practices resemble the consumption patterns of luxury fashion and, thus, draw a close link between sustainable and luxury consumption. Fuerst and Shimizu (2016) observe a similar relationship between sustainability and luxury in the field of real estate, where especially wealthier households are willing to pay a premium for eco-labelled condominiums, which the authors attribute to intangible benefits from living in an ecological building. Johnson et al. (2018) provide evidence that the consumption of pro-social products, similar to luxury products, can be triggered by the need for status in addition to the pro-social self-concept. Griskevicius et al. (2010) observe similar results - namely, that the activation of status motives leads people to buy green products. Finally, Berger (2017) could not find a positive signalling effect for either green or luxury products.

\subsection{CSR activities}

\subsubsection{Best practices}

Scholars provide evidence of best practices with respect to sustainability and CSR for a range of industries. They focus on the strategic level, discuss concrete 
examples for sustainable business practices, or investigate the financial impact of CSR and sustainability in the luxury industry.

4.6.1.1 What are sustainable business practices? Doval et al. (2013) provide an overview of environmentally friendly practices adopted by luxury companies along the value chain. They discuss examples for manufacturing (e.g., organic cotton), packaging (e.g., recycled paper packaging), operations (e.g., carbon tests), and CSR (e.g., environmental charter) in various industries, like jewellery, fashion, and hotels. Similarly, Karaosman et al. (2018) identify a range of different best practices along the supply chain of two Italian fashion and footwear producers, like waste reuse, wastewater treatment, certified raw materials, emission reductions, and renewable energy production. Yet, they also stress supply chain complexity, commercial pressures, and power distribution as factors impeding the implementation of sustainability in such a supply chain. Lerma et al. (2017) discuss an example of new eco-friendly materials to replace gold in jewellery.

4.6.1.2 What are successful strategic approaches? Carcano (2013) investigates how luxury companies effectively incorporate sustainability into their strategic management and identifies four strategic archetypes. These archetypes differ with respect to internally (employees, governance structure) versus externally (environment, community) oriented sustainability and with respect to the scope of the strategic approach (either corporate or spread across the company). Cimatti et al. (2017) discuss an example of a successful Italian brand that produces high-luxury leather and fabric accessories with recycled materials. Strategically, they stress craftsmanship; they do not focus on being eco, but on being exquisite.

4.6.1.3 What is the financial impact of incorporating sustainability and CSR? Overall, the identified articles argue for a positive impact of CSR and sustainability on financial performance. However, these articles only cover the hospitality industry. Sharma and Mishra (2018) find a positive effect of CSR on corporate performance of Indian luxury hotels. Thomas and James (2012) investigate best practices with respect to CSR in luxury hotels in Kumarakom, Kerala, and believe that the adoption of these practices will exert a positive effect on the financial performance of these hotels. Ahn and Pearce (2013) investigate the possibility for green building in the hotel industry, which also fosters luxury and financial success.

\subsubsection{Effect on consumers}

As CSR and sustainability are typically not implemented by companies for their own sakes but by following an economic rationale, their impact on consumers' perceptions and purchase decisions is of high relevance. Overall, the identified literature provides evidence that this impact is positive, albeit not always very strong. Moreover, several scholars analyse moderating effects. 
4.6.2.1 What are the consequences of engagement in CSR and sustainability? Based on Carroll's (1979) four CSR dimensions, Amatulli et al. (2018) investigate the effect of luxury companies' CSR initiatives on consumers' willingness to purchase their products. They observe a positive impact of initiatives located in the legal and philanthropic dimensions. Similarly, Cheah et al. (2016) confirm a positive impact of sustainable and ethical practices on the consumers' judgement of products. Rosenbaum and Wong (2015) ask guests of a five-star hotel in China about the positive influence of a green marketing program, finding that it is weaker than the effects of its value proposition, brand image, and reputation as well as its relationship programs. Olšanová et al. (2018) identify a positive attitude of luxury buyers towards CSR, yet these buyers are not very knowledgeable about CSR activities of particular brands and did not consider CSR strongly during past purchase decisions.

4.6.2.2 What are the consequences of not engaging in CSR and sustainability? Jin et al. (2017) provide evidence that engagement in CSR does not positively influence consumers' responses, but not engaging in CSR may result in negative consequences in terms of brand attitude and perception of credibility.

4.6.2.3 Which moderating effects can be observed? On the one hand, CSR activities can exert a moderating effect on other relationships. In the context of luxury cruisers, Shim et al. (2017) find a moderating effect of the CSR image on the relationship between other cruisers and brand distinctiveness. On the other hand, moderators can exert effects on relationships incorporating CSR and sustainability. Tascioglu et al. (2017) show a moderating effect of collectivism on the relationship between consumers' status motivation and the perception of the importance of a retailer's environmental and social sustainability; they also find a moderating effect of materialism on the relationship between status motivation and the retailer's social sustainability.

\subsection{Stakeholders}

\subsubsection{Effect of consumer characteristics}

Extant literature provides rich evidence that consumers differ with respect to their attitudes and purchasing decisions related to sustainable luxury. It analyses factors as diverse as status, risk, education, interest in luxury brands, dimensions of consciousness and values, motivation, culture, and gender.

4.7.1.1 Status Overall, status and status needs are positively related to sustainable luxury purchase. Kapferer and Valette-Florence (2019) show that richness in terms of "old money" mediated via hedonism leads to sustainable demand, whilst the perception of self-success is not related to this demand. Richness in terms of "old money" is linked to the desire to be distinct and to be sensitive to quiet signals, which can only be decoded by peers in the same social class (Kapferer and Valette- 
Florence 2019). Similarly, Zhang et al. (2018) provide evidence that high status positively affects attitude towards hotels' participation in CSR programs compared to low status needs, but only if the CSR message is easy to process. Ali et al. (2019) show that materialism and cultural value (horizontal-vertical collectivism and vertical individualism) positively moderate the positive relationship between status motivation and purchase intention of a green luxury car. Moreover, Chang et al. (2019) find that the evaluation of a luxury brand's CSR campaign is more positive by high-power individuals than by low-power individuals.

4.7.1.2 Risk Peng and Cheng (2019) provide evidence that perceived functional, financial, hedonistic, and self-image risks have a positive effect on hesitating to stay at a luxury hotel that implements green practices. Moreover, they find a moderating effect of green product knowledge on the relationship between functional and hedonistic risk and purchasing intentions.

4.7.1.3 Education Petersen and Wilcox (2016) find an effect of education on the perception of luxury brands in terms of sustainability. Their results indicate that people with higher education perceive luxury brands as being less socially conscious than people with lower education, whereas they perceive a socially responsible luxury brand as being more socially conscious than less-educated people do.

4.7.1.4 Interest in luxury brands Ahn (2015) provides evidence that the pricing of a luxury CSR product affects the perceived sacrifice of CSR motivation, although this effect depends on the interest in luxury brands: "consumers with relatively low interest in luxury brands perceived sacrifice of the CSR initiative to be higher than consumers with relatively high interest in luxury brands" (Ahn 2015, p. 1).

\subsubsection{Dimensions of consciousness and values Ki and Kim (2016) identify} seeking personal style and social consciousness, but not environmental consciousness, as drivers of sustainable luxury purchase. Shilpa and Madhavaiah (2017) also investigate the impact of different dimensions of consciousness on sustainable luxury consumption, with somewhat differing results, as they find that both social and environmental consciousness have a high impact on sustainable luxury consumption. Jain (2019) categorises factors affecting sustainable luxury purchase intentions into culture, self-oriented (personal) values, others-oriented (social) values, and economic value. These values are combined with the theory of planned behaviour and Schwartz's (1992) value theory to predict purchase behaviour. Ho et al. (2016) organise consumers according to their annual household income and value expressive perceptions, defining four segments; they show that the members of these segments respond differently to CSR initiatives of luxury brands. In addition, value expressive perceptions affect the attention paid to CSR initiatives. ${ }^{1}$

\footnotetext{
${ }^{1}$ This article was not accessible as full text. Thus, its discussion is based on the information provided in the abstract.
} 
4.7.1.6 Motivation Scholars provide several frameworks to categorise consumers according to their motivational drivers. Based on the self-determination theory, Gibson and Seibold (2013) construct a model of consumer behaviour in the context of luxury purchase that distinguishes different motivational types related to different behavioural patterns. Henninger et al. (2017) analyse Chinese consumers' motivational drivers with respect to the consumption of sustainable luxury fashion and identify four consumer types in this context, which lead to different behavioural patterns with respect to luxury. Rishi et al. (2015) explore the preferences of the Indian transition generation (25- to 44-year old) with respect to sustainability in the luxury lodging industry. They find three key drivers to motivating the purchase of sustainable luxury: influence of parents, children, and travel agents; rewards for green behaviour; and frequent communication around sustainability efforts.

4.7.1.7 Culture and gender Amatulli et al. (2017b) show that collectivist versus individualist cultural orientation affects whether consumers initiate negative wordof-mouth after perceiving shame triggered by unsustainable luxury products. Chen et al. (2016) provide evidence that ethical consumption is more important for women than for men.

\subsubsection{Compatibility of luxury and sustainability}

A large part of the research explicitly focuses on the compatibility between sustainability and luxury. Several scholars observe a perceived contradiction between luxury and sustainability, whilst others find factors that can foster the perception of their compatibility. A third group stresses that luxury has to become greener to remain competitive.

4.7.2.1 Perception of contradiction between luxury and sustainability In the discussion on the compatibility of luxury and sustainability within a focus group analysed by Beckham and Voyer (2014), respondents argue that normal luxury buyers prefer not to buy sustainable products whilst having positive reactions to sustainable luxury themselves. Achabou and Dekhili (2013) confirm this view of the normal luxury buyer. In their study of French luxury clothing, they show that incorporating recycled materials into luxury goods negatively affects consumers' preferences. They argue that "consumers are only willing to buy environmentallyfriendly clothing if the intrinsic quality attributes, such as style and colour, are equivalent to those of conventional products" (p. 1901). Janssen et al. (2017) observe that relative brand conspicuousness negatively influences consumers' CSR beliefs about responsible luxury brands, in the sense that for more conspicuous brands CSR beliefs are less favourable. Pinto et al. (2019) find a complex relationship between luxury brands and the perception of ethicality. They show that luxury brands are associated with sophisticated brand personality and that sophisticated brands are perceived to be less ethical than sincere brands. The findings of Kapferer and Michaut-Denizeau (2014) seem to support this perspective, as many of their respondents - all of them luxury buyers-consider luxury and 
sustainability to be somewhat contradictory. Kapferer and Michaut (2015) address this contradiction and show that the way consumers define luxury influences the degree of perceived contradiction. In contrast, Davies et al. (2012) argue that the tendency of consumers to consider ethics and sustainability in their purchasing behaviour is significantly lower when purchasing luxury goods compared to other purchases. Thus, it is a matter of not only compatibility, but also attention paid to sustainability in luxury purchase. This observation is supported by Mathur et al. (2019), who find that consumers do not actually consider sustainability when selecting a luxury chain hotel in Deli.

4.7.2.2 How to achieve compatibility De Angelis et al. (2017) compare the effectiveness of two possible strategies for luxury fashion producers to introduce new green products. In cases when consumers with high brand knowledge are targeted and the product is durable, their empirical results suggest making green products similar to the luxury company's previous non-green products rather than similar to the products of non-luxury green companies. Hence, the perception of luxury has to be the focus. Moraes et al. (2017) present a similar result. They investigate the ethical luxury consumption of jewellery and conclude that "if ethics and sustainability dimensions are to be embedded in fine jewellery consumption practice, they must first be made an intrinsic part of the nexus of the social and material environment of trading and consumption places" (Moraes et al. 2017, p. 525). De-Miguel-Molina et al. (2011) also confirm this. They investigate a possible link between luxury and sustainability (with a focus on the environmental dimension) in relation to luxury resorts in the Maldives. They observe that luxury is not necessarily linked with sustainability, but it is possible to link both. Thus, luxury and sustainability are not related naturally, but consumers' perception processes have to be influenced in a manner that reveals this relationship. Several authors provide evidence regarding possible influencing factors to achieve this. For example, Janssen et al. (2014) investigate the effects of scarcity and ephemerality on the perception that luxury and CSR are compatible. They observe a moderating effect of ephemerality on the positive impact of scarcity on consumers' perception of fit between luxury and CSR. Aybaly et al. (2017) analyse the compatibility between sustainability and luxury in the automotive industry and discuss Tesla as an example where luxury and sustainability are concurrent, despite Tesla not initially positioning its roadster as luxury. However, according to the authors, it is perceived as a luxury due to the high price. Nationality is also important, as Dekhili et al. (2019) observe. They find that sustainability information can negatively affect the perceived quality of luxury goods based on the consumers' nationality. French consumers did not change their perceptions whereas Saudi consumers did. Torelli et al. (2012) find that, under certain conditions, CSR information has negative effects on luxury brands' evaluation due to the incompatibility of luxury's selfenhancement concept (dominating resources and people) versus the self-transcendence concept (considering the welfare of all) related to CSR. However, this negative effect can be mitigated by particular luxury brand concepts not in conflict with CSR. Line and Hanks (2016) observe that the compatibility of luxury and 
green management in the hospitality industry depends on the destination image. According to their results, "while the belief that green hotels are less luxurious translates to unfavorable attitudes toward green hotels in urban tourism destinations, this relationship does not occur in nature-based tourism destinations" (Line and Hanks 2016, p. 904). Gnjidic and Vukovic (2018) find diametrically opposite levels of CSR practices, staff behaviour, and general managers' attitudes in Croatian luxury hotels. These differences result from the general difference in managing the hotels. These results show that the compatibility of luxury and sustainability-at least in the hospitality industry—also depends on the management approach.

\subsubsection{Compatibility as necessity Olorenshaw (2011) discusses the consequences} of the most recent financial crisis on luxury brands and their importance of becoming more "ethical". Meanwhile, Thomas (2018) stresses the need for luxury, including luxury goods, to become more sustainable. Cervellon (2013) investigates the meaning of sustainable luxury for wealthy customers and finds that participants expected a brand with more luxury to be more sustainable, thereby supporting previous arguments in favour of sustainability as a means to remain competitive in the luxury industry. Pavione et al. (2016) examine the major drivers of the integration of sustainability and CSR into the competitive strategies of luxury companies. They focus on innovative sustainable business models in the luxury industry.

\subsubsection{Paradox of consumerism}

The paradox of consumerism-namely, the gap between behavioural intentions and actual behaviour in terms of sustainability (e.g., Vermeir and Verbeke 2006)—is also an issue in the luxury literature. Several scholars provide evidence with respect to this gap; others try to find solutions to narrow it.

4.7.3.1 Evidence regarding the paradox of consumerism Arrington (2017) complains that many consumers in the luxury context claim to consider ethical issues in their purchasing decisions but are not willing to spend more for ethical products. Similarly, De Klerk et al. (2019) find that, although their participants expressed strong ethical concerns, they almost never engaged in environmentally significant behaviour.

4.7.3.2 Remedies to the paradox of consumerism Han et al. (2017) strive to provide marketers with insights into how to educate consumers to engage in more sustainable fashion products' consumption. They state that consumers experience a constantly imbalanced psychological state between their sustainability concerns and their personal consumption behaviour. Marketers should provide experiences to consumers to reduce this imbalance and encourage a more sustainable consumption. Joy et al. (2012) investigate the gap between consumers' attitudes towards sustainability and their consumption of unsustainable, fast fashion products. They further argue that only true luxury fashion is capable of satisfying the needs of these 
consumers for luxury fashion whilst simultaneously fostering environmental sustainability.

\subsubsection{Management and staff}

Only a small number of papers deal with the perception of staff and managers on CSR and sustainability in the luxury industry. They focus on the perceived advantages and actual practices.

4.7.4.1 Perceived advantages Results reveal that initiatives in this area seem to be beneficial in terms of staff work satisfaction, but less in terms of business success. Cheyne and Barnett (2001) find evidence that most of the asked managers in hotels and luxury lodges in New Zealand judge the implementation of environmental programs as advantageous in terms of improving customer and employee satisfaction as well as relationships with local communities, whereas fewer managers deemed these programs to be advantageous in terms of marketing. Sourvinou and Filimonau (2018) find that the implementation of environmental management programs in luxury hotels, which comprise outlining the benefits of environmental management interventions, incentivised participation, regular evaluation, and adequate training, exert a positive impact on hotel staff's job satisfaction and organisational commitment amongst hotel staff and their environmentally responsible behaviour outside work.

4.7.4.2 Actual practices Melo et al. (2012) show that, although decision-makers in luxury hotels in Natal/RN, Brazil, are interested in CSR, business practices still need further improvements in this area. Wisler (2018) does not find evidence of a moral philosophy difference between the ethical decision-making process of chief executive officers in U.S.-led and European-led strategic business units within the luxury goods industry. "The themes and emergent findings resulting from the qualitative analysis indicate a profound incompatibility between the values informing decision-makers using the luxury strategy and those employed by leaders operating within the principles and parameters of responsible leadership and conscious capitalism" (Wisler 2018, p. 443).

\subsubsection{Regulators and researchers}

Within this category, the implementation of trade labels and certificates is analysed. One research instrument is introduced, and consequences of missing official controls are discussed.

4.7.5.1 Fair trade labels and certificates Several authors focus on fair trade gold programs in developing countries, particularly those in sub-Saharan Africa. Hilson (2008) suggests applying fair trade labels to the gold mined in developing countries and discusses the differences between small-scale agriculture and artisanal gold mining, like the somewhat illegality of the latter. Hilson et al. (2018) criticise that 
these programs often do not empower or at least target impoverished mining groups and argue that there is a high variability in terms of what constitutes "fair" throughout the supply chain. In contrast to fair trade initiatives for coffee, which help different actors along the supply chain, the structures in the mining industry inhibit the empowerment of the poor miners to a certain extent. Childs (2008) and Childs (2014) discuss the possibility and the disadvantages of these programs and also criticise that small-scale miners are overlooked. Moreover, Blackman et al. (2014) analyse the effects of the Blue Flag beach certification program in Costa Rica and find a positive impact of this program on new hotel investment, particularly in luxury hotels and economically advantaged communities.

4.7.5.2 What to do if controls are missing Sadovy de Mitcheson et al. (2018) argue that, in the case of shark fins, international control systems fail to stop the uncontrolled overfishing and the possible extinction of species; therefore, fins should be taken off the menu to stop this exploitation of threatened species.

4.7.5.3 Research instrument Woodside and Fine (2019) provide the sustainable fashion research grid to foster research in sustainable fashion.

\section{Discussion and conclusion}

As argued in the introductory sections of this article, luxury is a very fast-growing sector (Donzé and Wubs 2019); although attitudes do not always result in corresponding actions, it cannot be denied that consumers are increasingly demanding sustainable products (Tomkins et al. 2018). In this context, many researchers have contributed valuable insights to various aspects of sustainable luxury, but the structured literature analysis discussed in this article also indicates the urgent need for a future research agenda along several paths. In the following paragraphs, those paths will be outlined, drawing on the most important possible future research activities.

Carrigan et al. (2017) raise the issue of small players in a luxury supply chain, and their problems to stick to CSR and sustainable practices. If luxury companies want to become truly sustainable, they have to establish truly sustainable supply chains (Karaosman et al. 2018). Research should provide further evidence of how they can afford this and which measures have to be taken to allow small players in this supply chain as well to provide their share. Moreover, as the discussion by Csaba and Skjold (2018) shows, what sustainability actually means along a whole supply chain has to be clarified.

The identified literature exhibits possible parallels between luxury and green products. However, several authors also show differences (e.g., DiDonato and Jakubiak 2016). This mixed evidence resembles the literature on compatibility between luxury and sustainability (see Sect. 4.7.2). Possibilities for linking both concepts seem to be influenced by rather complex mechanisms. In this context, a more structured analysis of which products are more suitable to combine luxury and 
sustainability is needed. Future research could identify the products with characteristics that make a combination of luxury and sustainability promising from both a business and societal perspective.

The expected impact of CSR and sustainability on the balance sheet is one major issue for luxury companies across all industries. However, only three papers in our analysis address this question. With respect to the impact of CSR on financial performance in general (independent of the luxury industry), the evidence is mixed (Alshehhi et al. 2018; Kumar et al. 2018; Miller et al. 2018). It would be interesting to determine whether this result can be replicated within the luxury industry or if, within this industry, with its particularities, a clear positive or even negative effect can be observed.

Interestingly, several authors analyse the effects of engaging in CSR, but only Jin et al. (2017) investigate consequences of not engaging in CSR. However, as several authors within this review discuss (e.g., Kapferer 2014; Bendell and Thomas 2013), becoming sustainable seems to be a necessity for the luxury industry to remain competitive; thus, further research with respect to not being sustainable, particularly within different industries, seems warranted. As the diversity of the covered industries within this overview shows, the luxury industry is a large sector covering a wide range of different products. Consumers might differ in terms of their tolerance regarding the absence of sustainability with respect to different products.

Furthermore, the question of how luxury companies should communicate their sustainable activities still offers room for further research activities. It has long been known that addressing green aspects of products could evoke negative connotations amongst buyers (Visser et al. 2018); this might be a risk amongst luxury consumers as well. Therefore, we suggest that researchers analyse different product categories within the luxury sector to provide suitable advice. Within this research area, consumers' various cultural backgrounds and their demographics (e.g., gender, age, income) may also influence the most promising way for companies to communicate to their target groups. Future research projects should take this into account.

Another area where more research attention is needed can be found within the field of internal marketing. Questions about how sustainable activities influence staff motivation and work satisfaction have been heavily discussed within various industries (Koch et al. 2019; Barakat et al. 2016; Supanti et al. 2015), but despite the works of Cheyne and Barnett (2001) and Sourvinou and Filimonau (2018) analysed in our literature review, this important discussion has not yet been at the centre of sustainable luxury research.

Finally, a possibly under-researched area constitutes the use of fair trade labels within the luxury industry. Our literature analysis demonstrates that the use of such labels within the luxury sector has-with the exception of Steinhart et al. (2013), who took a more general approach-thus far only been discussed in the context of gold and tourism. Other luxury sectors have not been considered. This offers plenty of opportunities for further research projects.

Like any research, our review also suffers from limitations. In particular, we focused on literature written in English, which might have led to the omission of research published in other languages that could contain particular insights into other cultural areas. Therefore, we see an additional path for future research in terms 
of a review of the literature published in other languages to identified insights, which are unobservable for readers unfamiliar with these languages. Despite this limitation, the present literature review provides profound insights with respect to the current state of the art of sustainable luxury in the internationally visible research and presents important paths for future research.

Open Access This article is licensed under a Creative Commons Attribution 4.0 International License, which permits use, sharing, adaptation, distribution and reproduction in any medium or format, as long as you give appropriate credit to the original author(s) and the source, provide a link to the Creative Commons licence, and indicate if changes were made. The images or other third party material in this article are included in the article's Creative Commons licence, unless indicated otherwise in a credit line to the material. If material is not included in the article's Creative Commons licence and your intended use is not permitted by statutory regulation or exceeds the permitted use, you will need to obtain permission directly from the copyright holder. To view a copy of this licence, visit http:// creativecommons.org/licenses/by/4.0/.

\section{Appendix}

See Tables 1, 2, 3, and 4 .

Table 1 The quantitative search results after 45 search runs, sorted by hits

\begin{tabular}{|c|c|c|c|c|}
\hline Search & Database & Search words & Hits & $\begin{array}{l}\text { Relevant } \\
\text { hits }\end{array}$ \\
\hline 29 & $\begin{array}{l}\text { Ebsco Business Source } \\
\text { Premier }\end{array}$ & Eco and luxury & 1 & 1 \\
\hline 32 & Ingenta & Eco and luxury & 1 & 1 \\
\hline 30 & $\begin{array}{l}\text { Ebsco Business Source } \\
\text { Premier }\end{array}$ & Organic luxury & 4 & 0 \\
\hline 26 & ABI/INFORM Collection & Eco and luxury & 5 & 3 \\
\hline 11 & Ingenta & Luxury and CSR & 9 & 5 \\
\hline 16 & $\begin{array}{l}\text { Ebsco Business Source } \\
\text { Premier }\end{array}$ & Responsible and luxury & 23 & 10 \\
\hline 37 & Scopus & $\begin{array}{l}\text { Corporate social responsibility AND } \\
\text { luxury }\end{array}$ & 29 & 16 \\
\hline 10 & $\begin{array}{l}\text { Ebsco Business Source } \\
\text { Premier }\end{array}$ & Luxury and CSR & 36 & 20 \\
\hline 31 & Ingenta & Green luxury & 40 & 5 \\
\hline 44 & Scopus & Eco and luxury & 41 & 13 \\
\hline 21 & Ingenta & Ethical and luxury & 45 & 6 \\
\hline 17 & $\begin{array}{l}\text { Ebsco Business Source } \\
\text { Premier }\end{array}$ & Responsibility and luxury & 51 & 23 \\
\hline 42 & Scopus & Ethical AND luxury & 51 & 13 \\
\hline 18 & $\begin{array}{l}\text { Ebsco Business Source } \\
\text { Premier }\end{array}$ & Ethical and luxury & 52 & 18 \\
\hline 28 & $\begin{array}{l}\text { Ebsco Business Source } \\
\text { Premier }\end{array}$ & Green luxury & 57 & 22 \\
\hline 45 & Scopus & Organic luxury & 57 & 1 \\
\hline
\end{tabular}


Table 1 continued

\begin{tabular}{|c|c|c|c|c|}
\hline Search & Database & Search words & Hits & $\begin{array}{l}\text { Relevant } \\
\text { hits }\end{array}$ \\
\hline 40 & Scopus & Responsible AND luxury & 60 & 8 \\
\hline 2 & $\begin{array}{l}\text { Ebsco Business Source } \\
\text { Premier }\end{array}$ & Luxury and sustainability & 74 & 29 \\
\hline 41 & Scopus & Responsibility AND luxury & 78 & 17 \\
\hline 6 & $\begin{array}{l}\text { Ebsco Business Source } \\
\text { Premier }\end{array}$ & Luxury and sustainable & 83 & 29 \\
\hline 43 & Scopus & Green luxury & 93 & 14 \\
\hline 33 & Ingenta & Organic luxury & 105 & 1 \\
\hline 38 & Scopus & Sustainability AND luxury & 120 & 23 \\
\hline 7 & Ingenta & Luxury and sustainable & 127 & 11 \\
\hline 3 & Ingenta & Luxury and sustainability & 129 & 19 \\
\hline 19 & Ingenta & Responsible and luxury & 149 & 15 \\
\hline 20 & Ingenta & Responsibility and luxury & 149 & \\
\hline 39 & Scopus & Sustainable AND luxury & 159 & 28 \\
\hline 12 & Science Direkt & Luxury and CSR & 213 & \\
\hline 9 & ABI/INFORM Collection & Luxury and CSR & 589 & 24 \\
\hline 35 & Science Direkt & Eco and luxury & 922 & 15 \\
\hline 27 & ABI/INFORM Collection & Organic luxury & 1481 & 10 \\
\hline 24 & Science Direkt & Ethical and luxury & 1659 & 11 \\
\hline 36 & Science Direkt & Organic luxury & 2237 & 7 \\
\hline 1 & ABI/INFORM Collection & Luxury and sustainability & 2683 & 35 \\
\hline 15 & ABI/INFORM Collection & Ethical and luxury & 3019 & 17 \\
\hline 25 & ABI/INFORM Collection & Green luxury & 3618 & 27 \\
\hline 34 & Science Direkt & Green luxury & 3782 & 14 \\
\hline 23 & Science Direkt & Responsibility and luxury & 4263 & 13 \\
\hline 5 & ABI/INFORM Collection & Luxury and sustainable & 4273 & 45 \\
\hline 22 & Science Direkt & Responsible and luxury & 4688 & 10 \\
\hline 13 & ABI/INFORM Collection & Responsible and luxury & 5679 & 28 \\
\hline 4 & Science Direkt & Luxury and sustainability & 6303 & 16 \\
\hline 8 & Science Direkt & Luxury and sustainable & 6318 & 16 \\
\hline \multirow[t]{2}{*}{14} & ABI/INFORM Collection & Responsibility and luxury & 6476 & 34 \\
\hline & & *Identical to responsible and luxury & & 673 \\
\hline
\end{tabular}




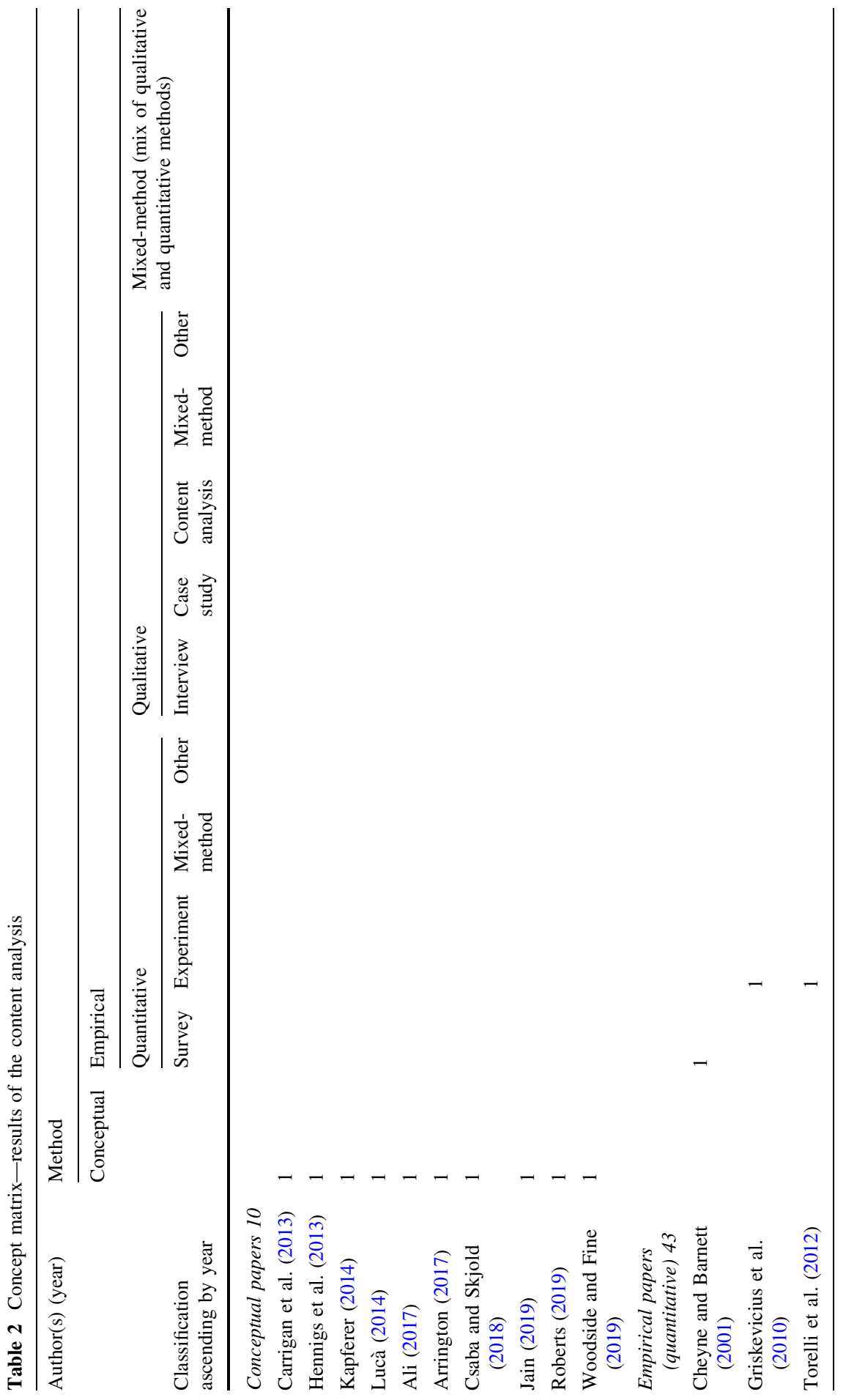




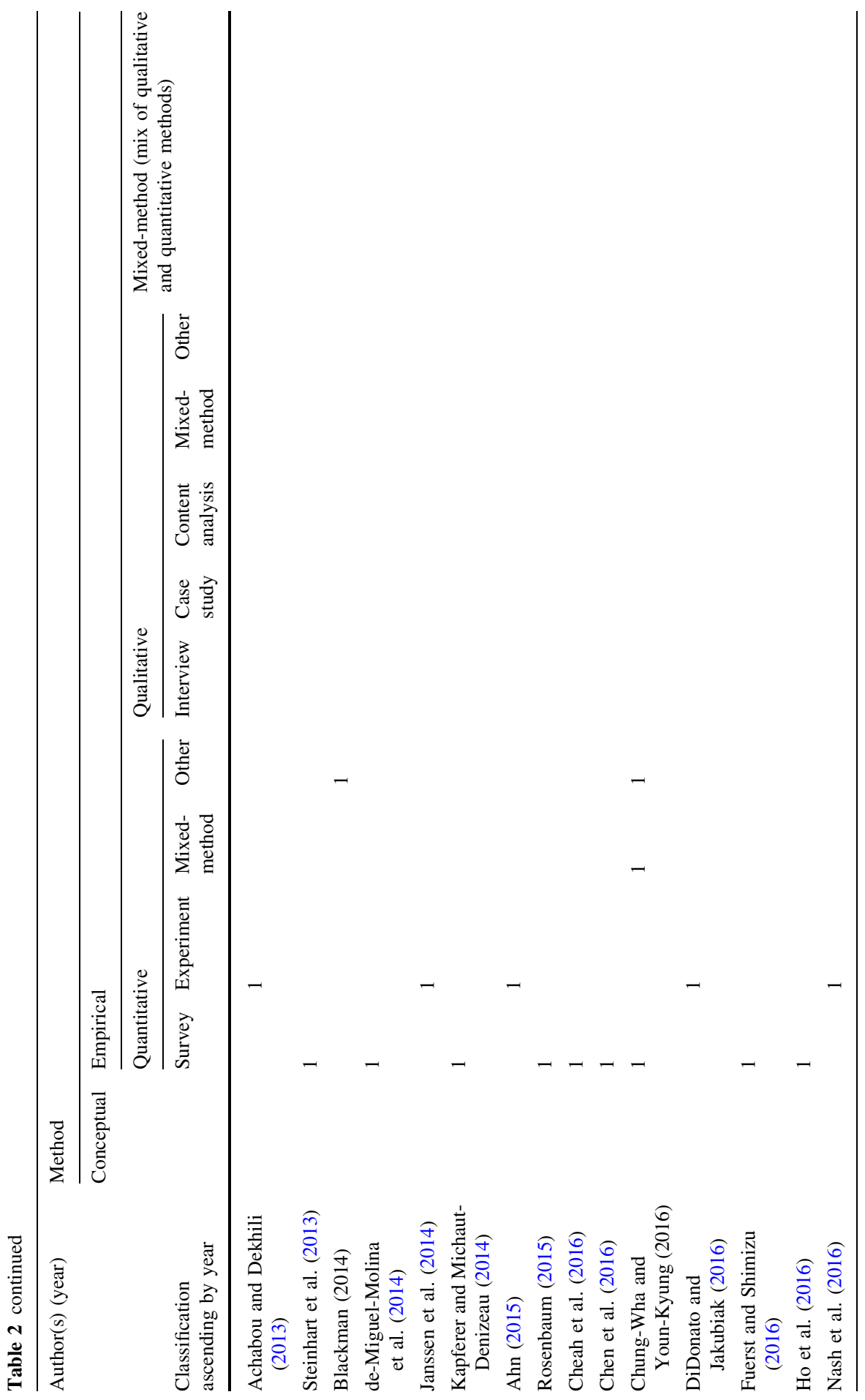




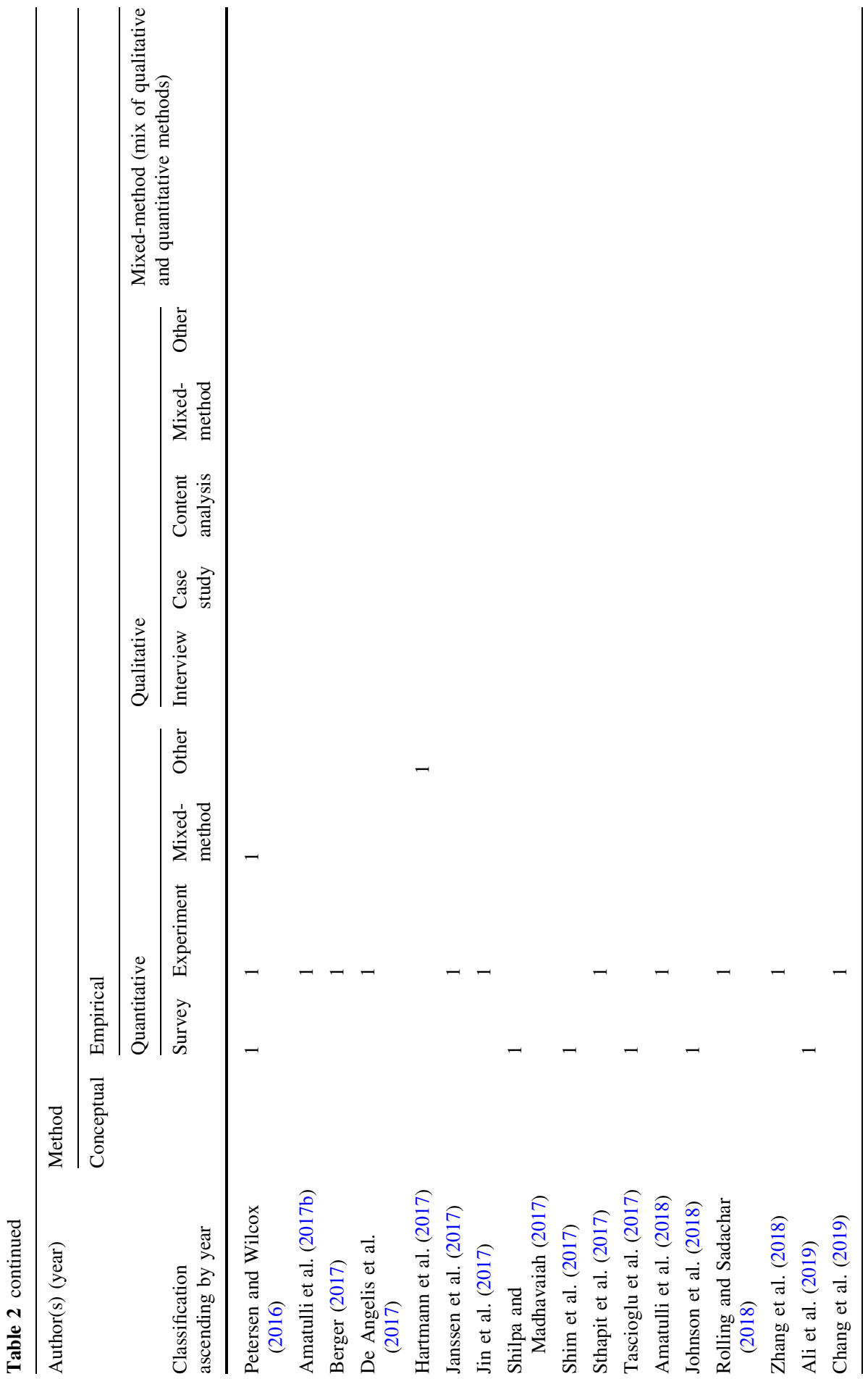




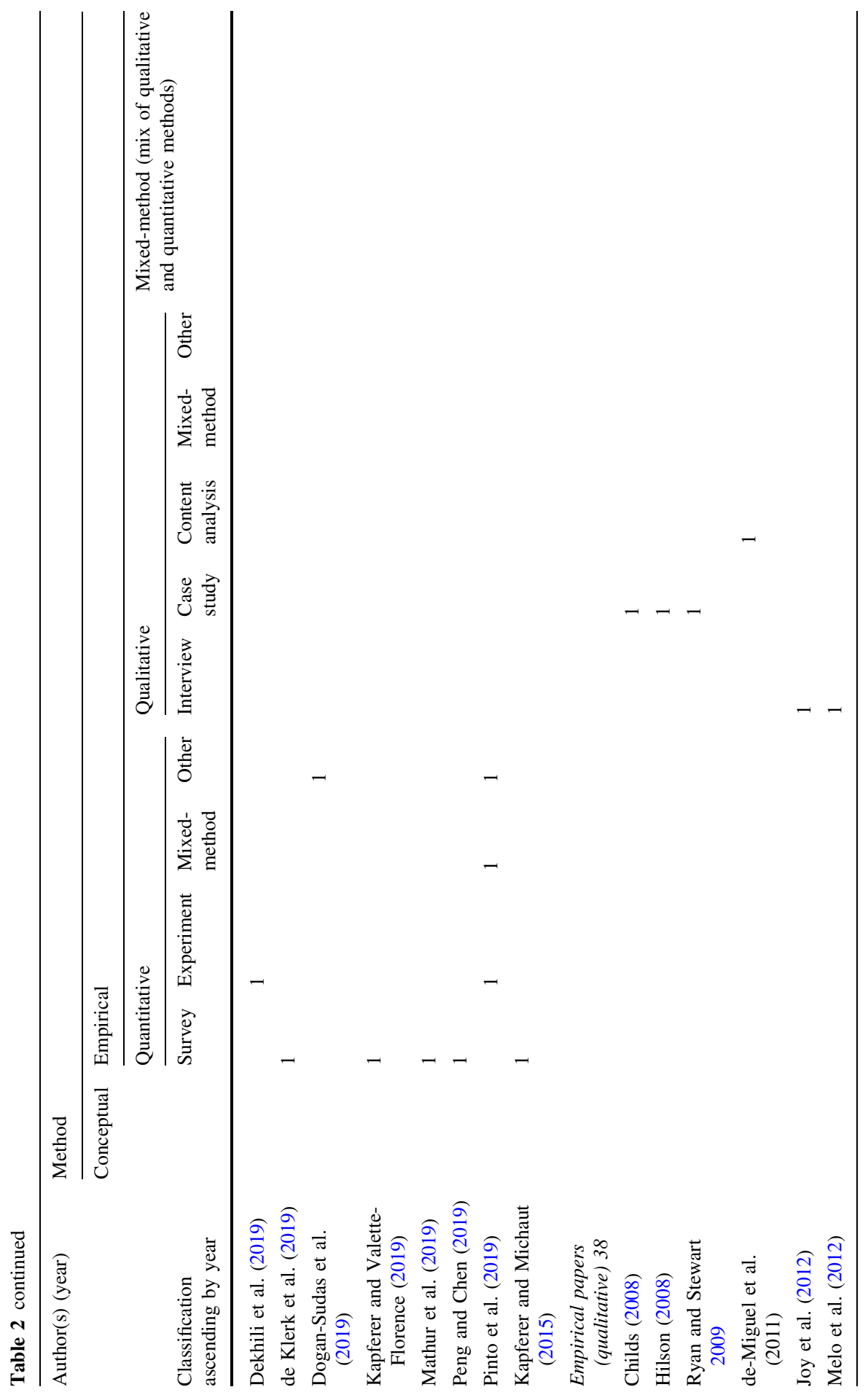




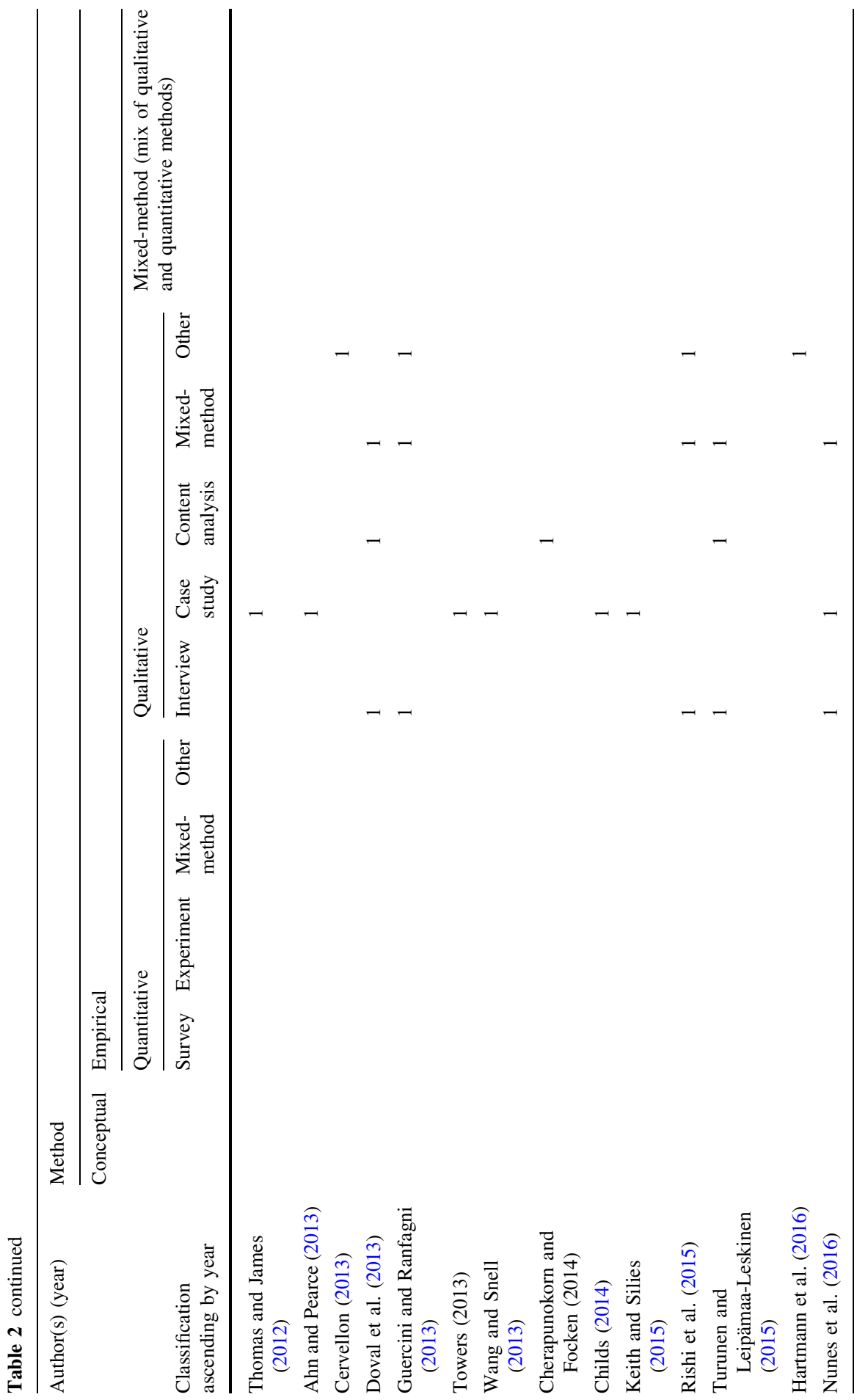




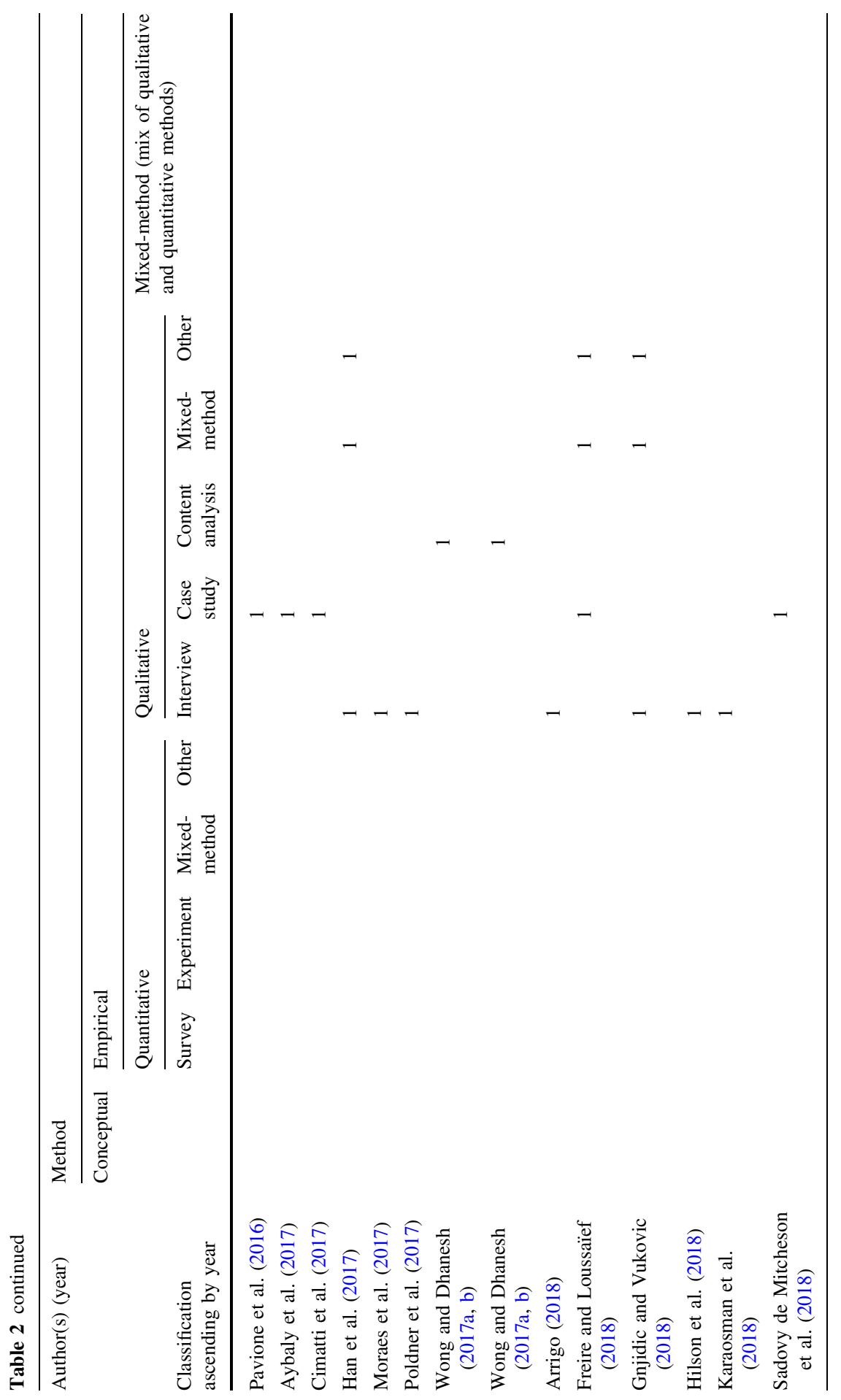




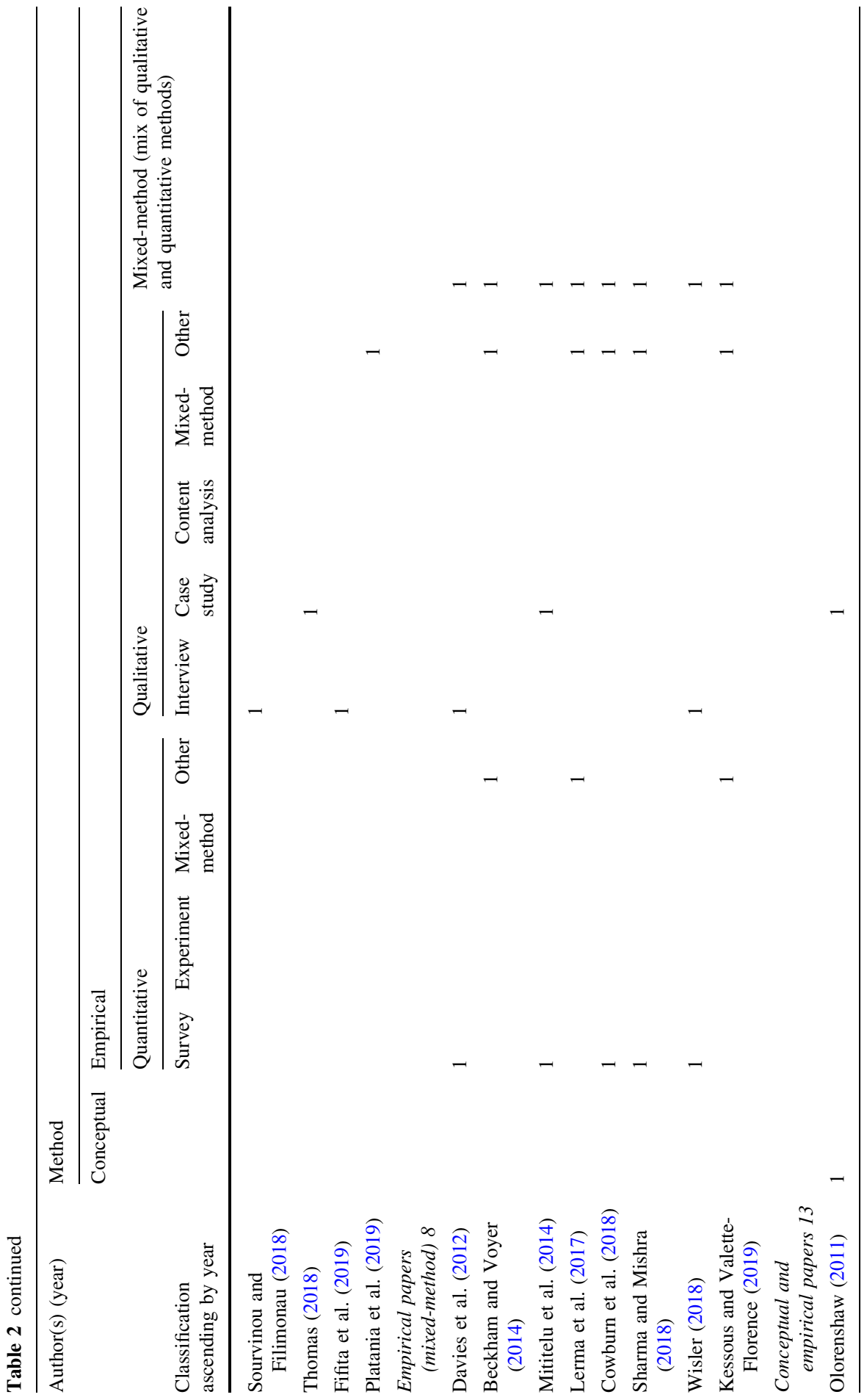




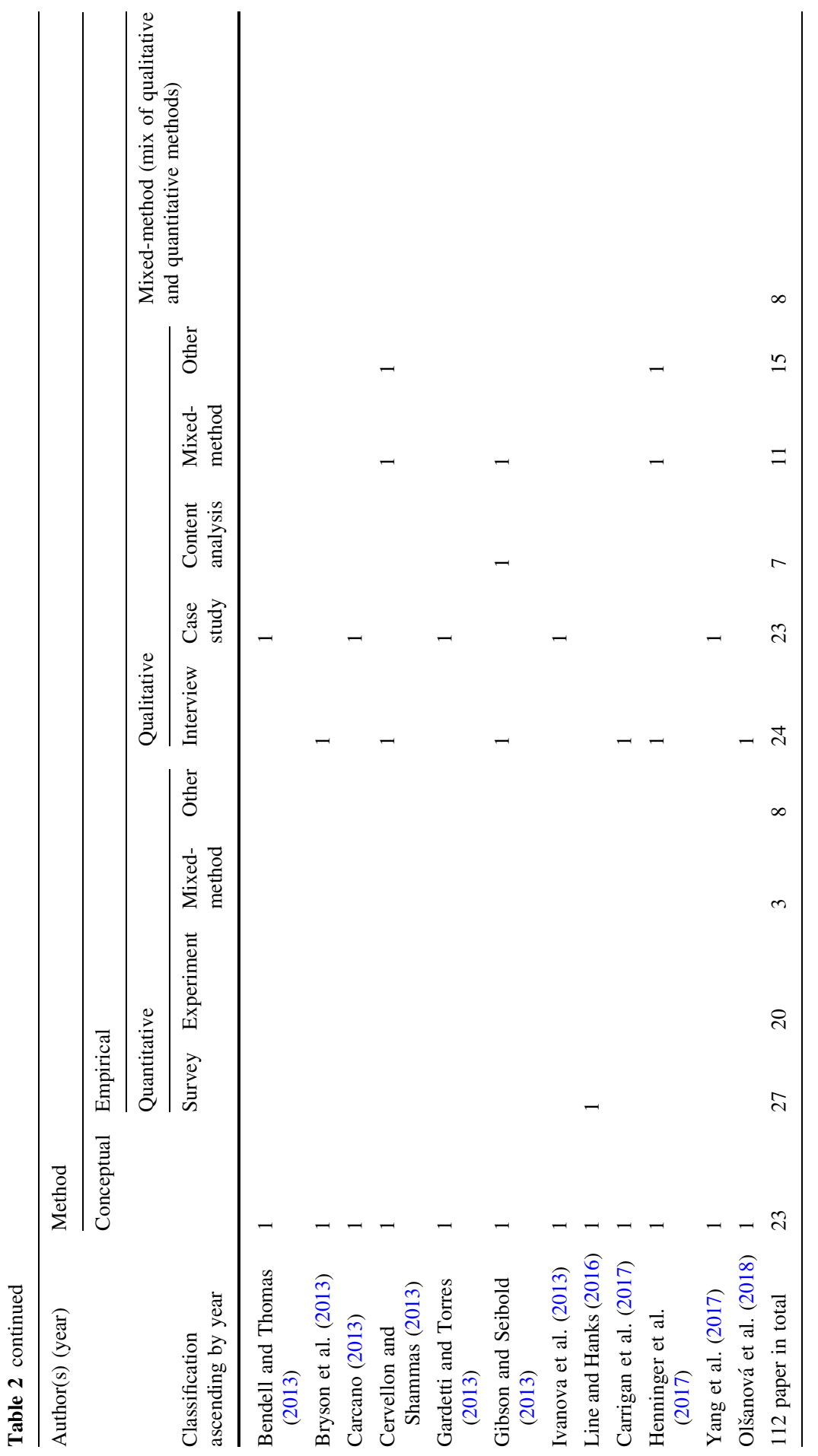




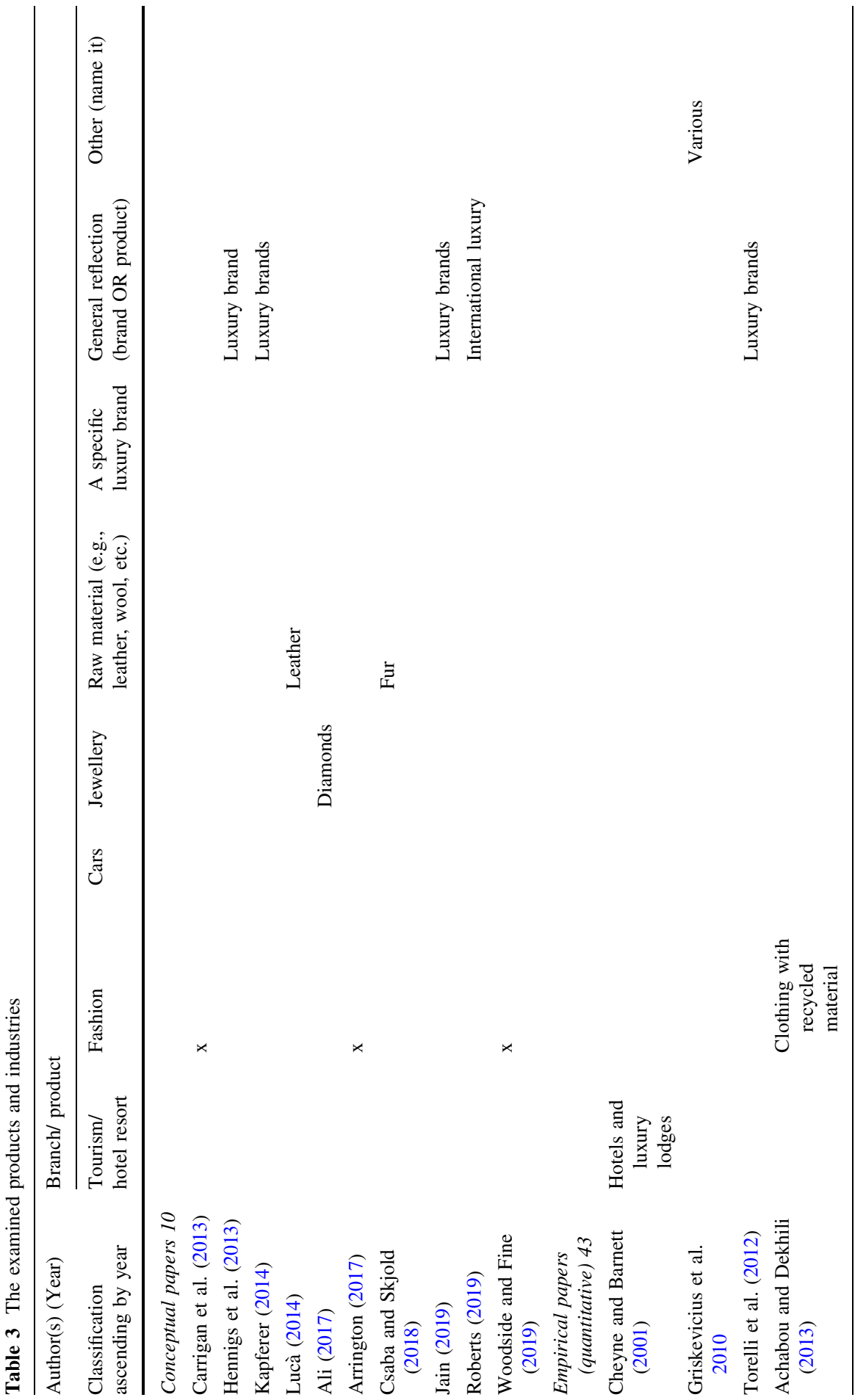




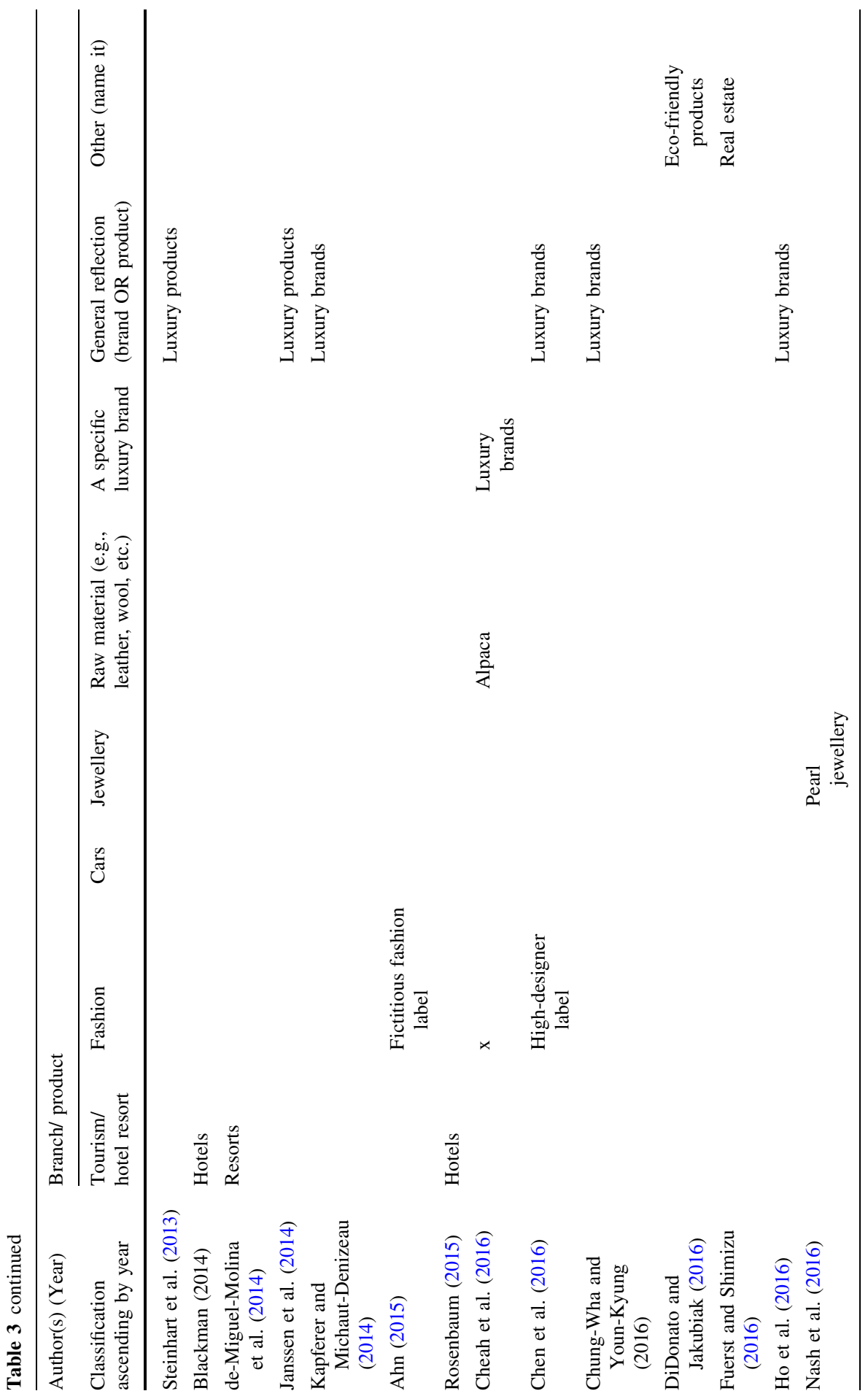




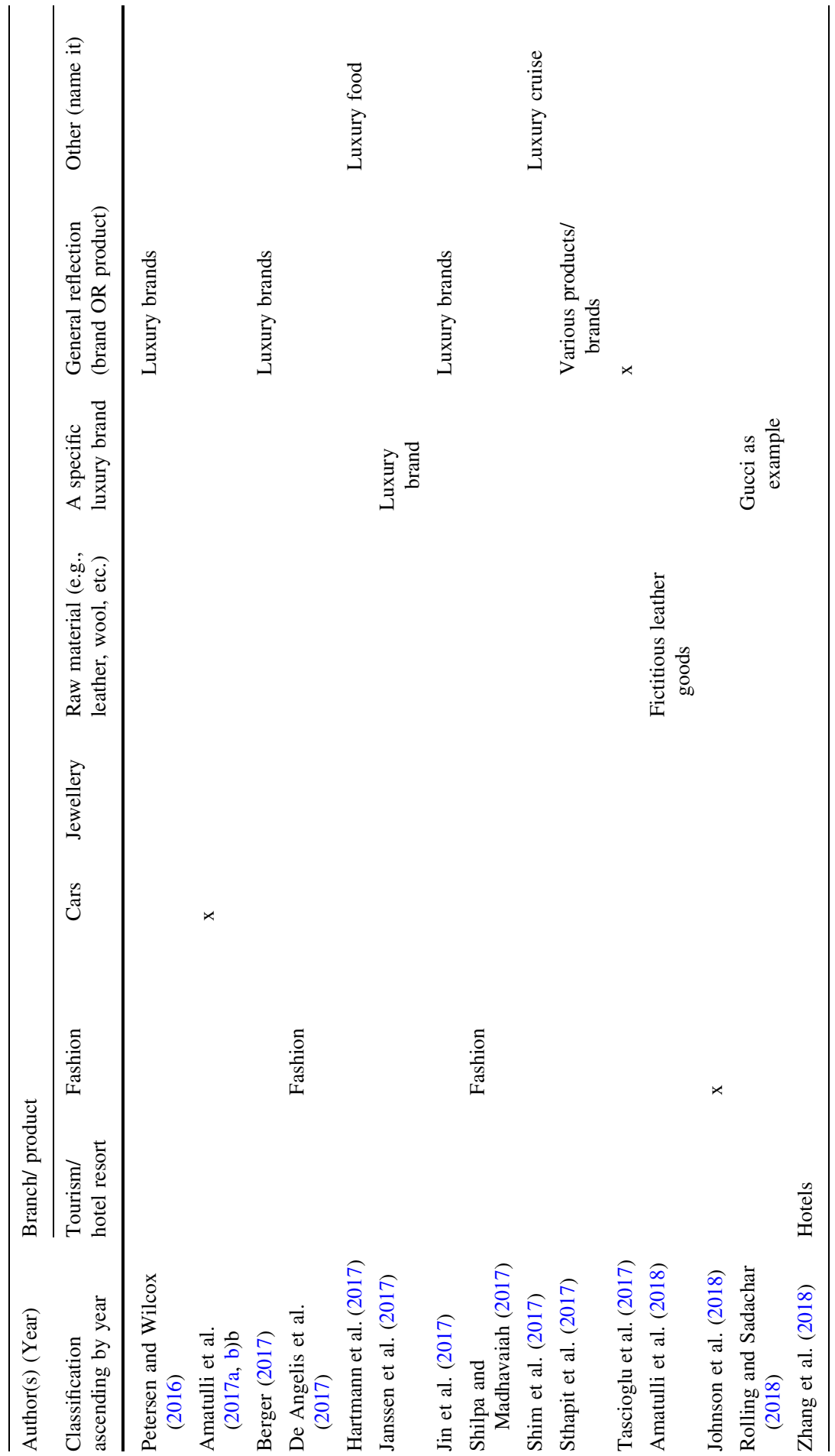




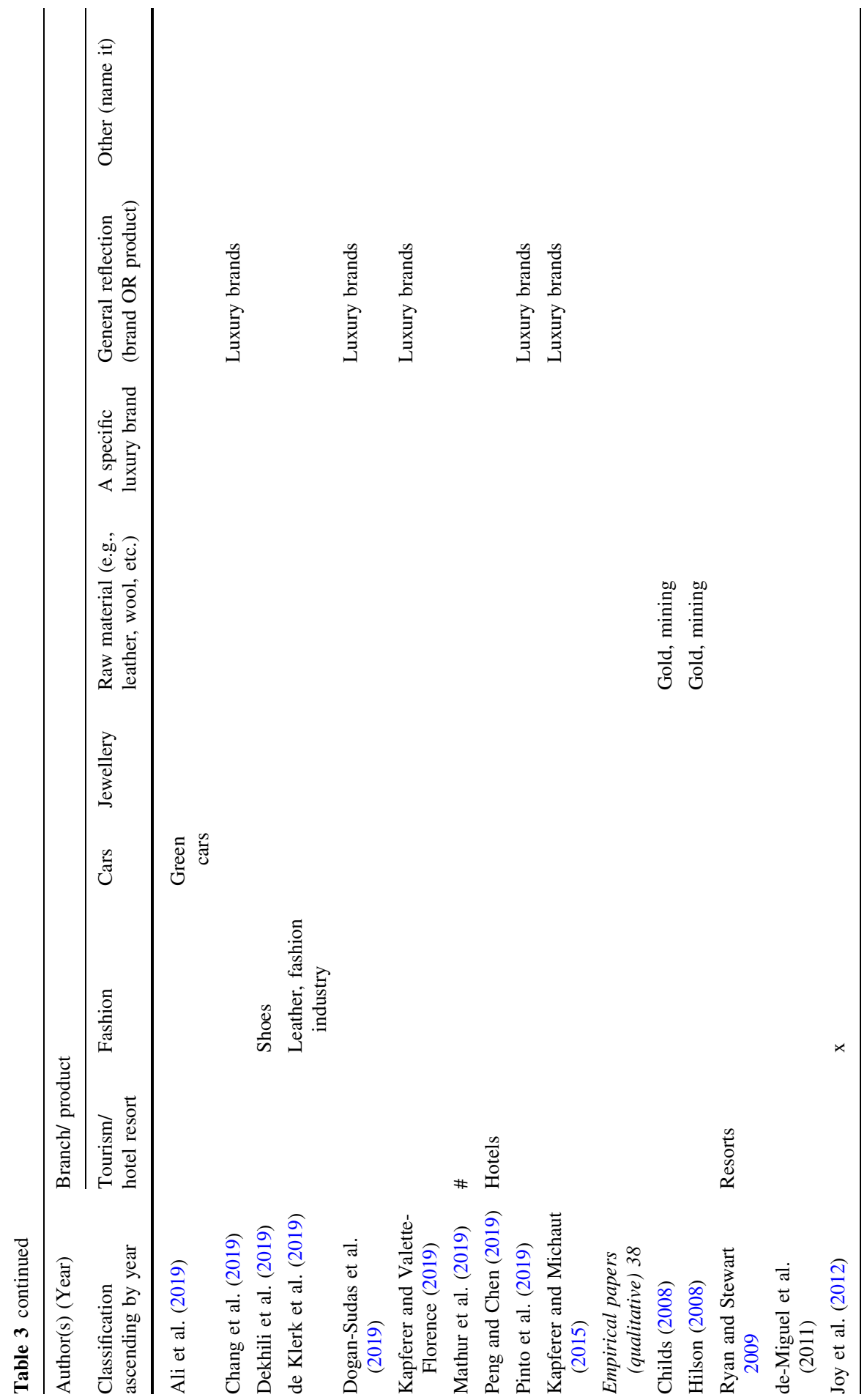




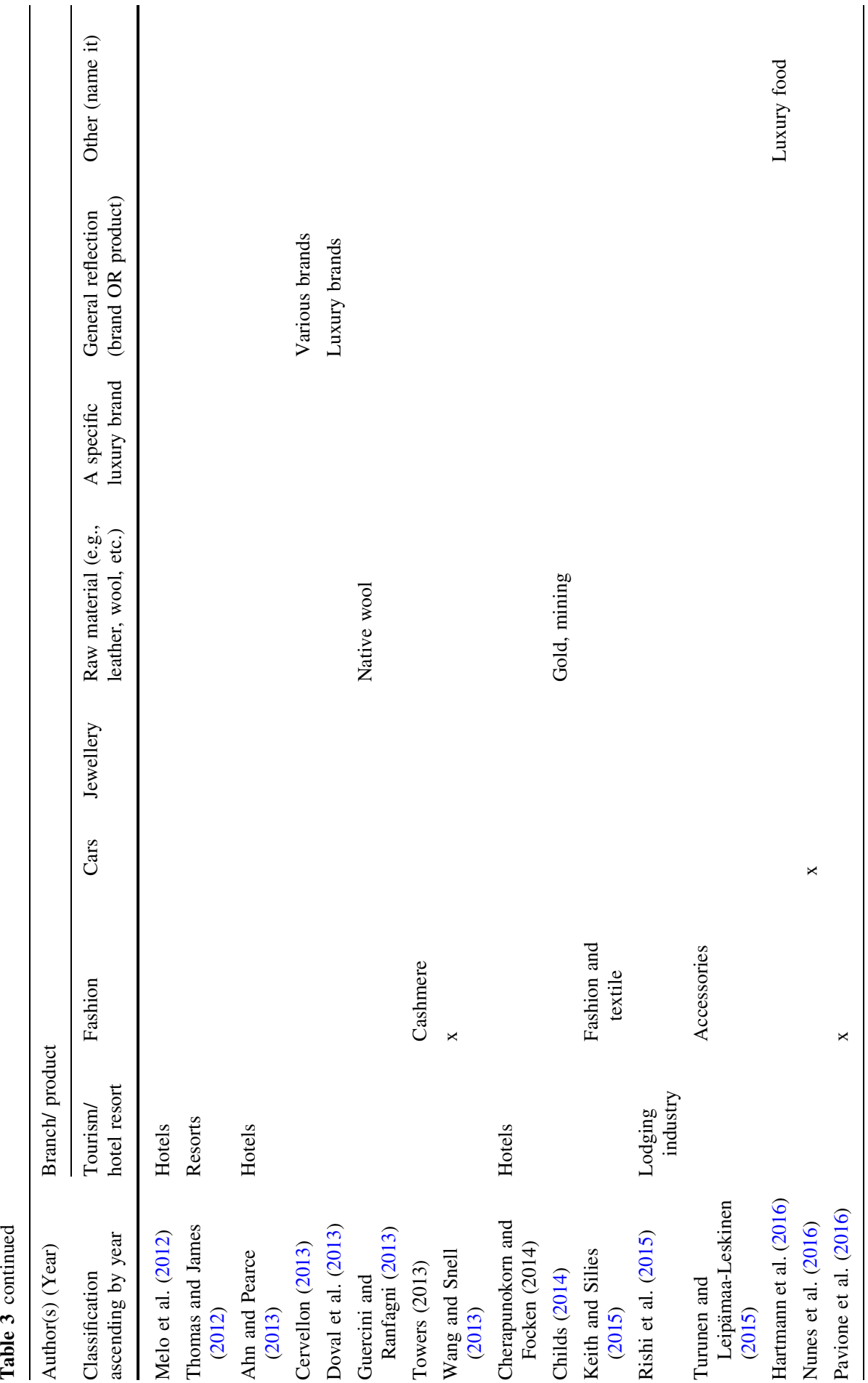




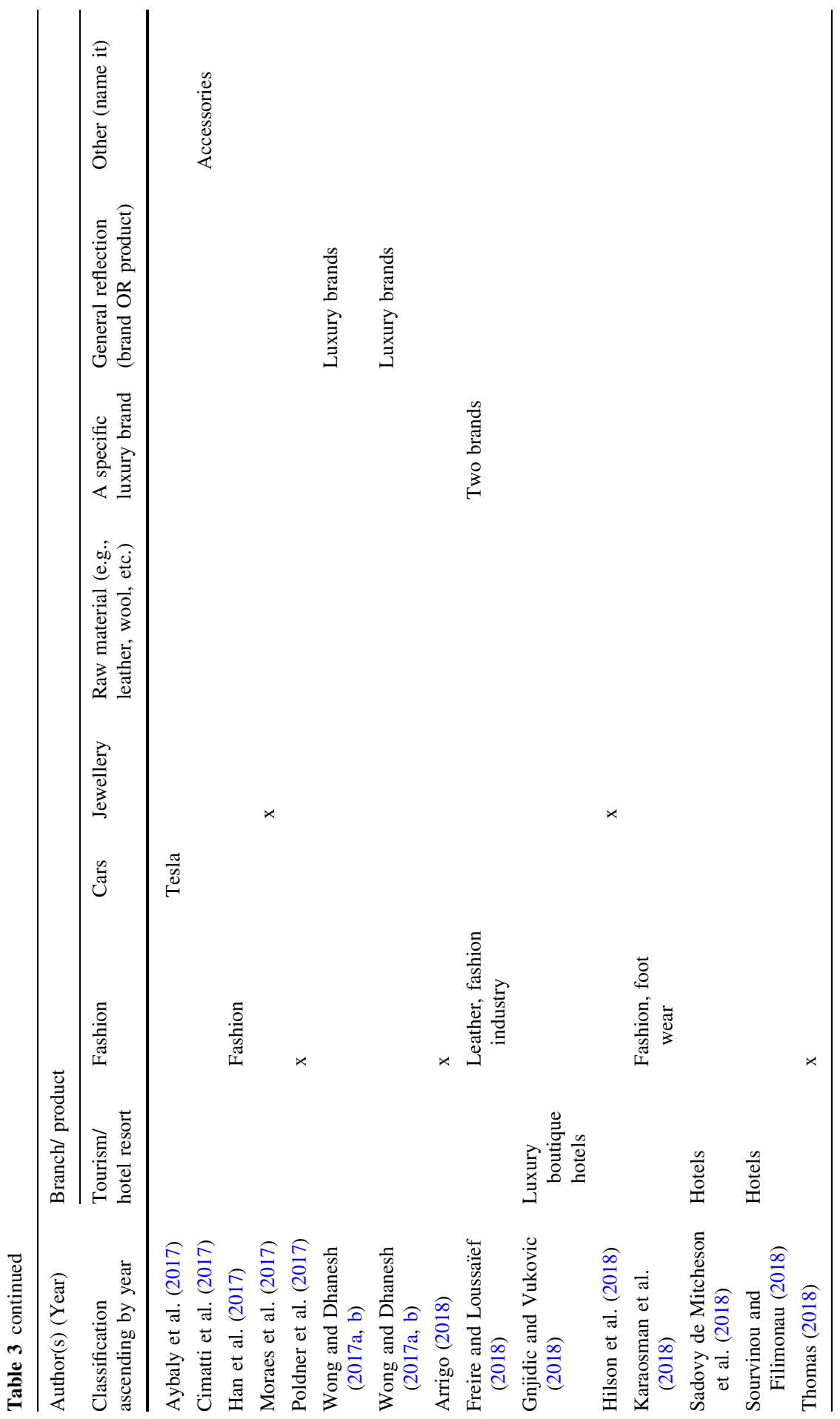




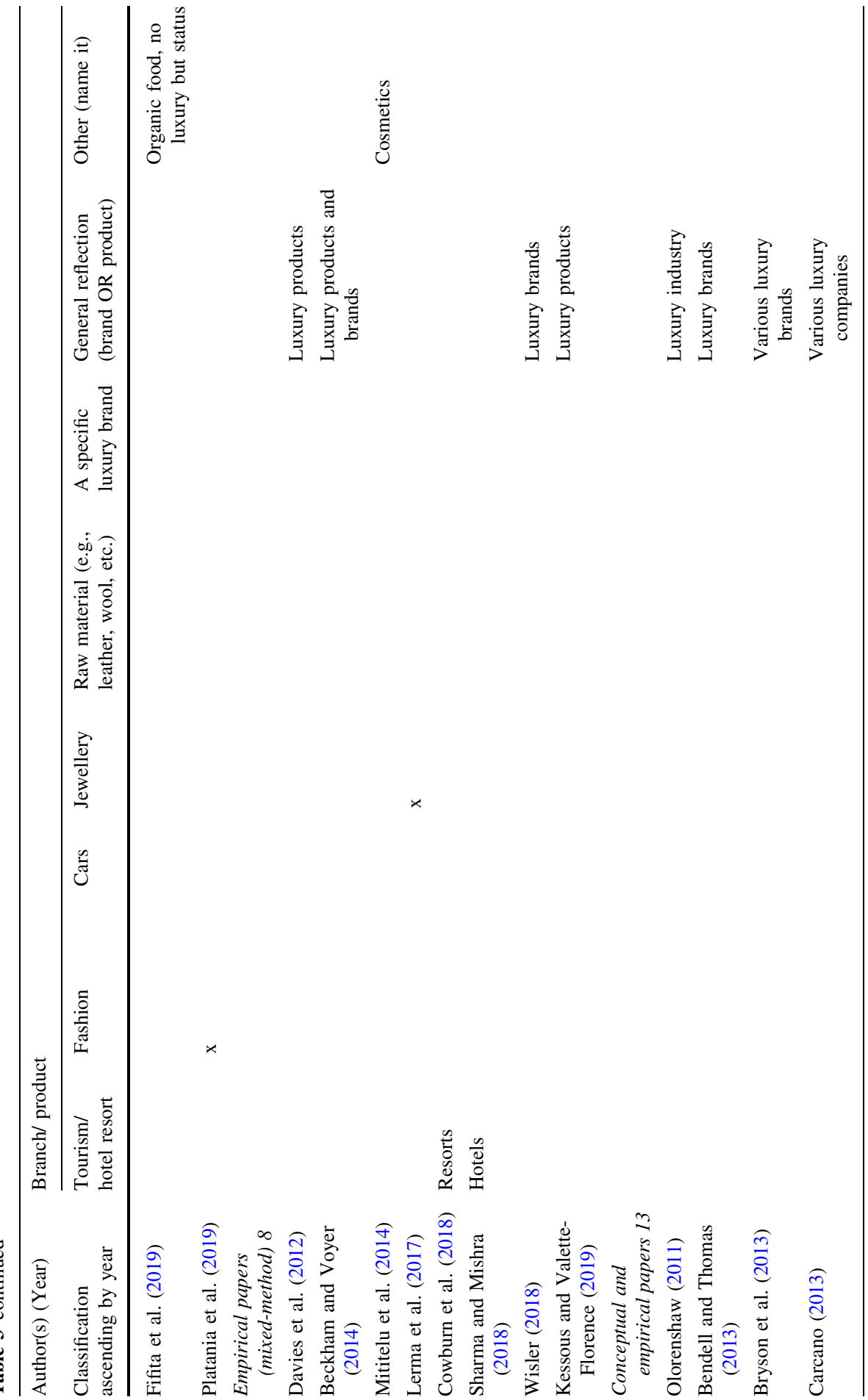




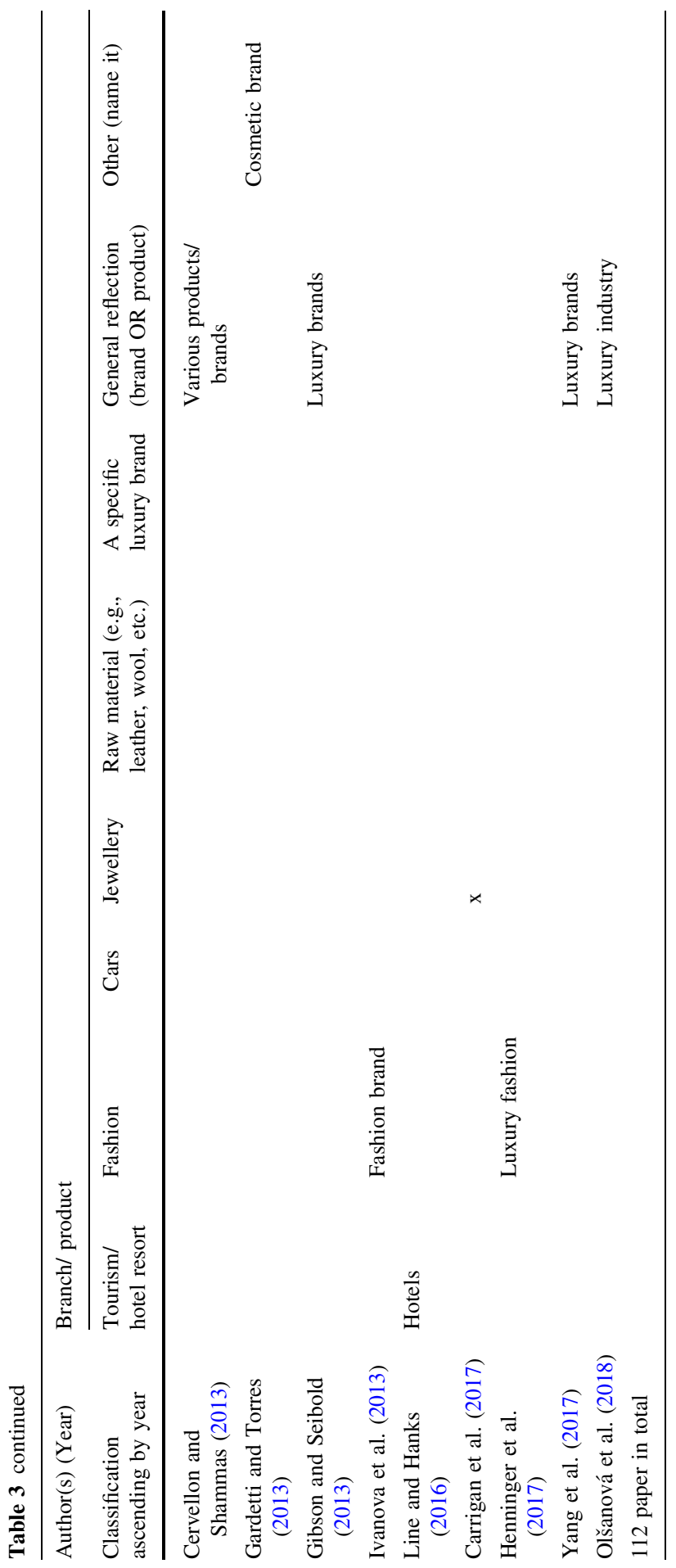




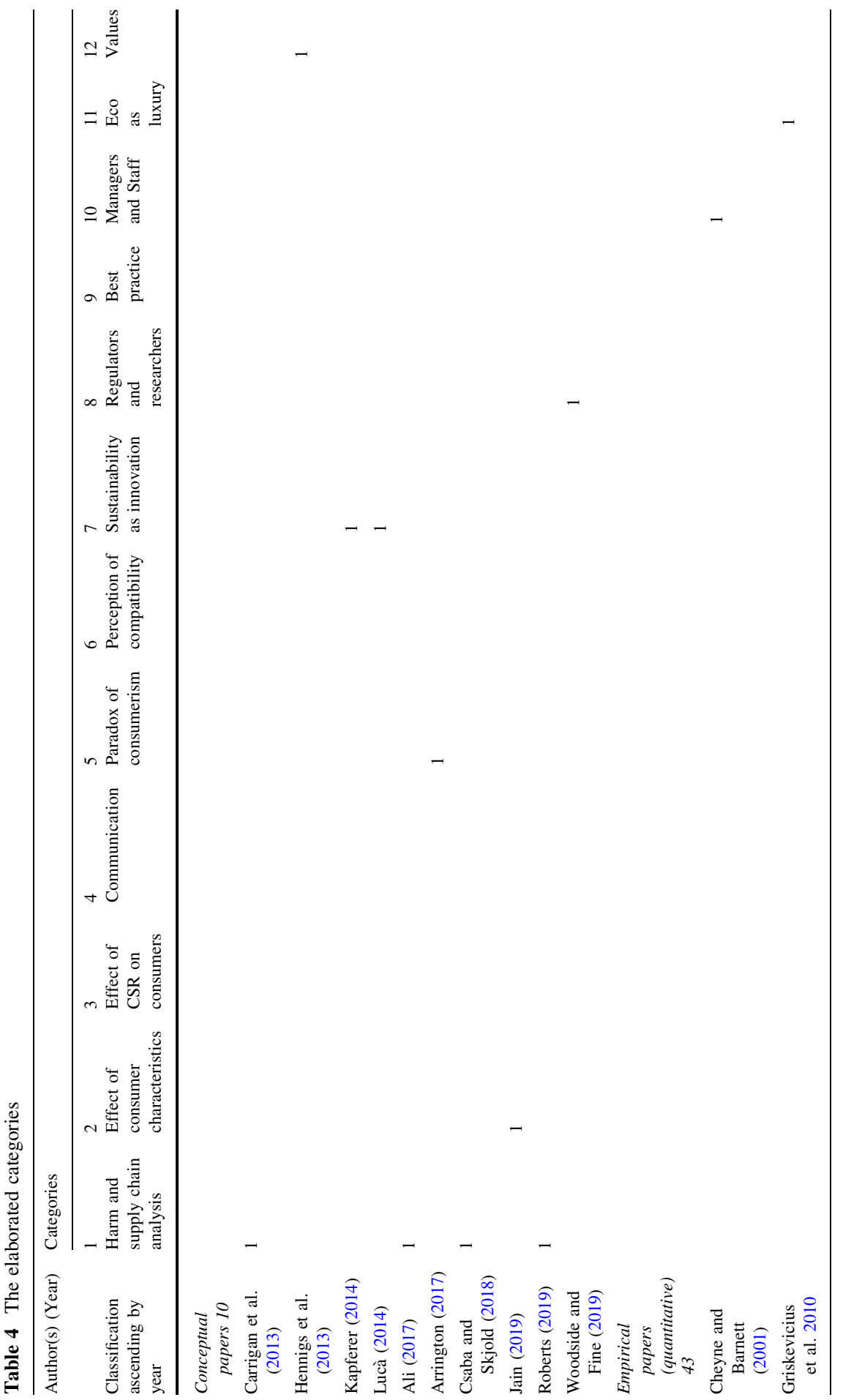

\section{Springer}




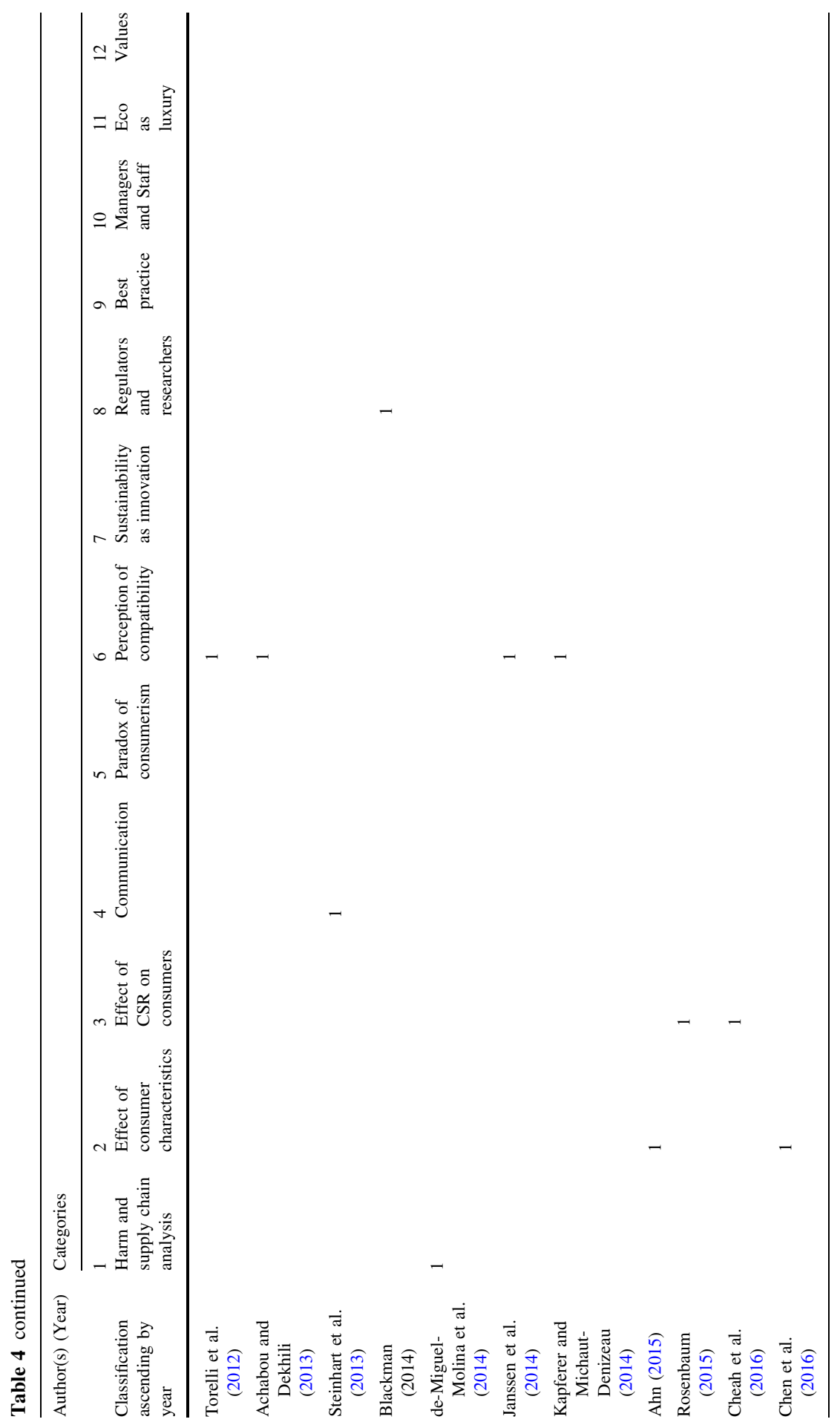




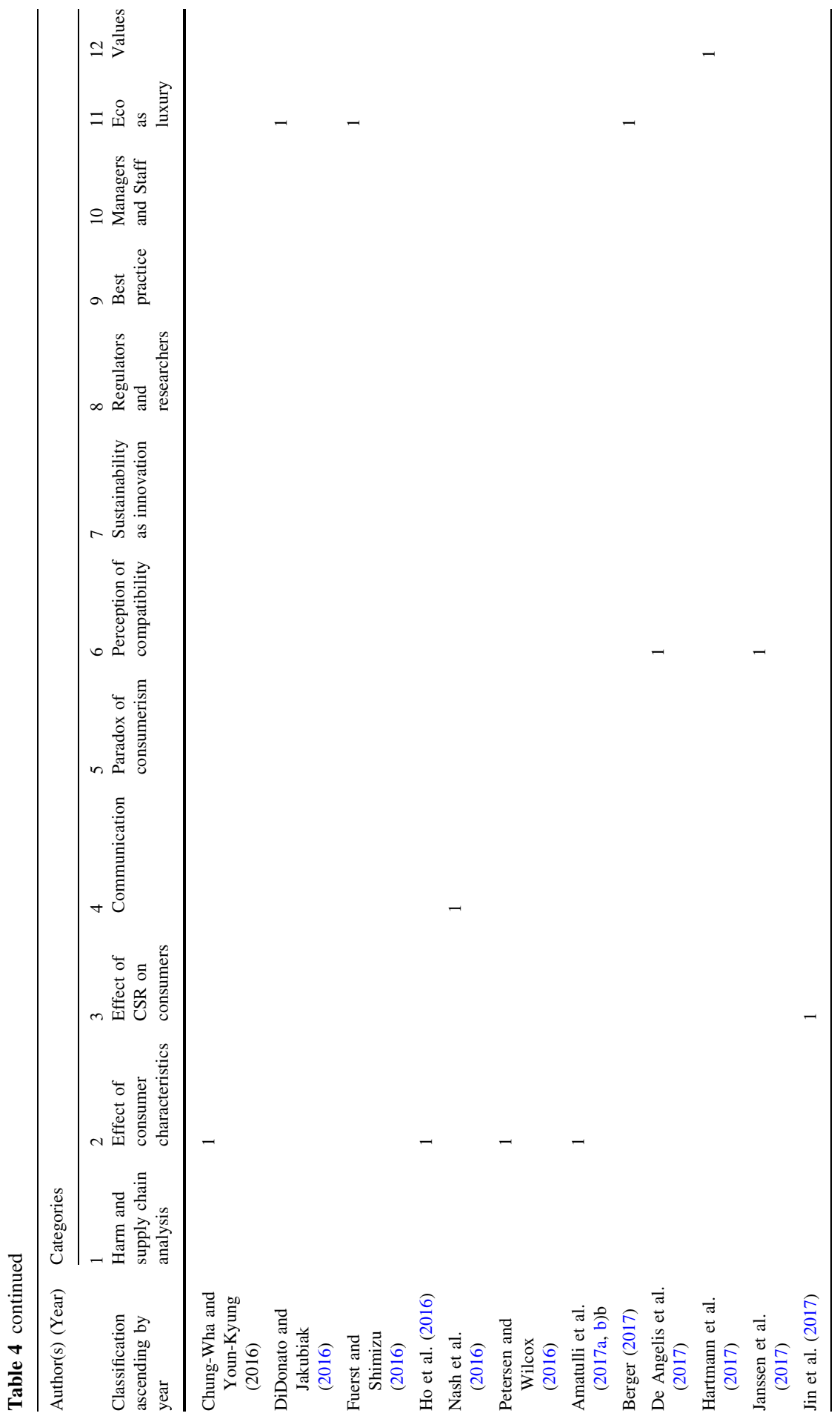




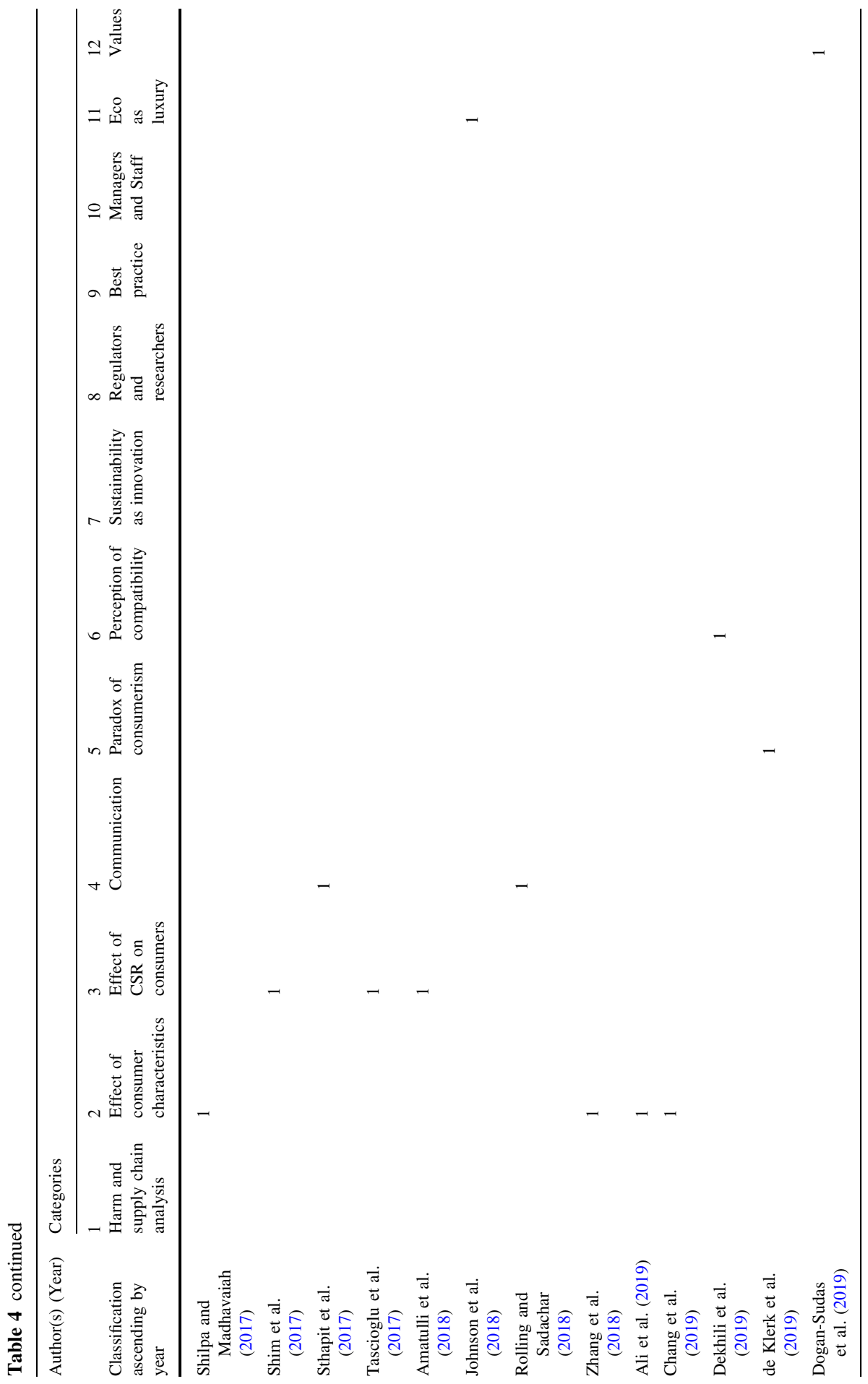




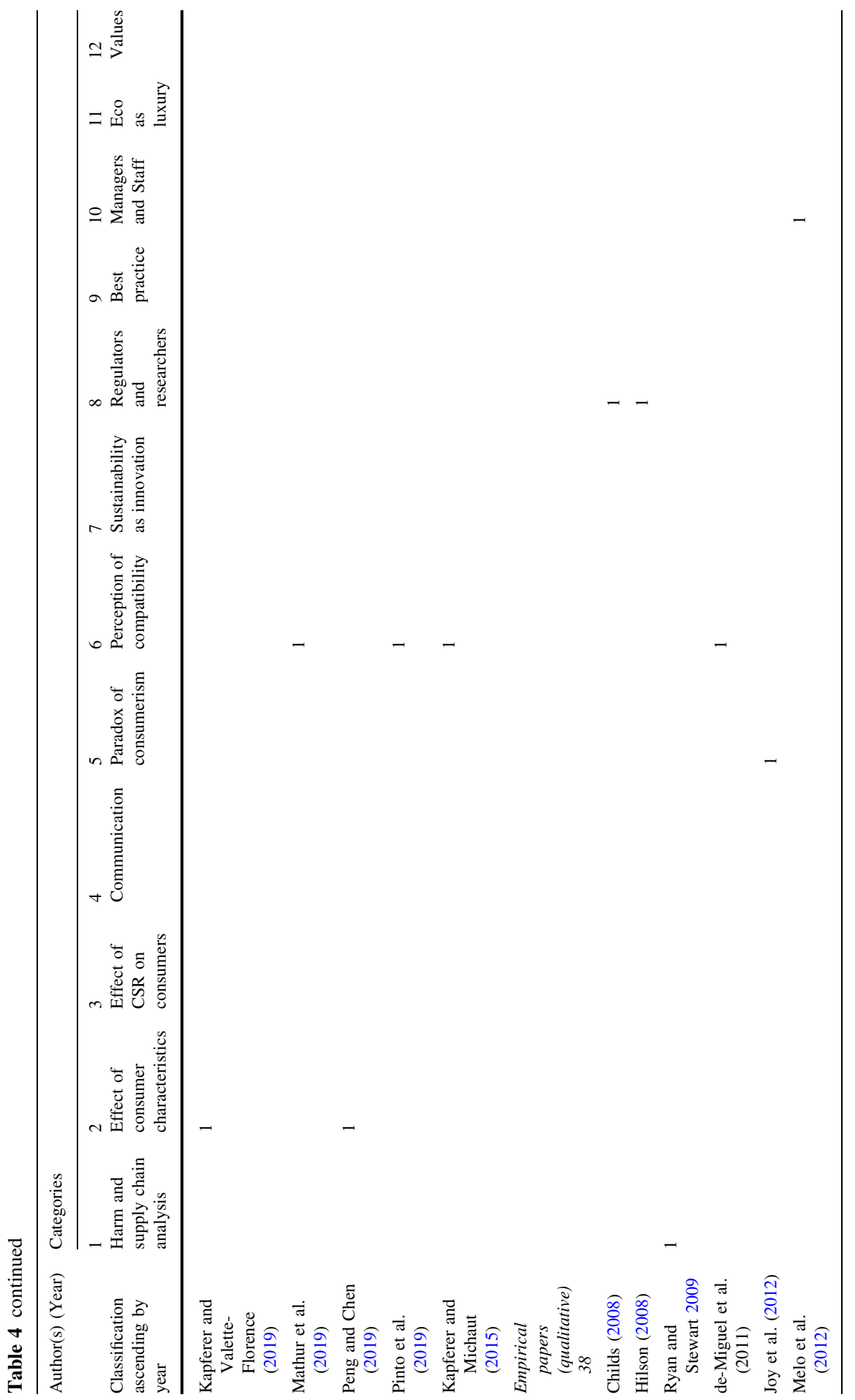




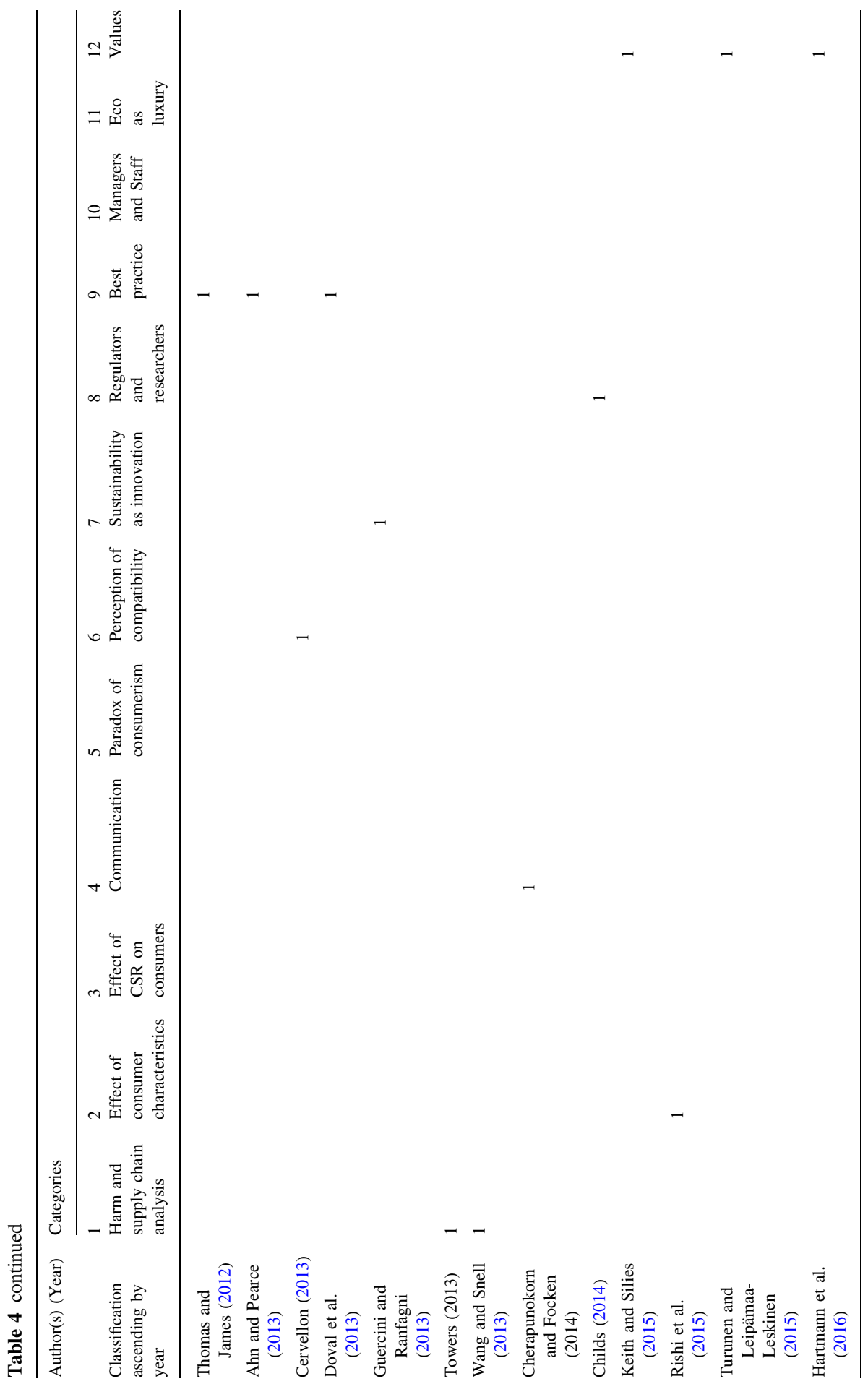




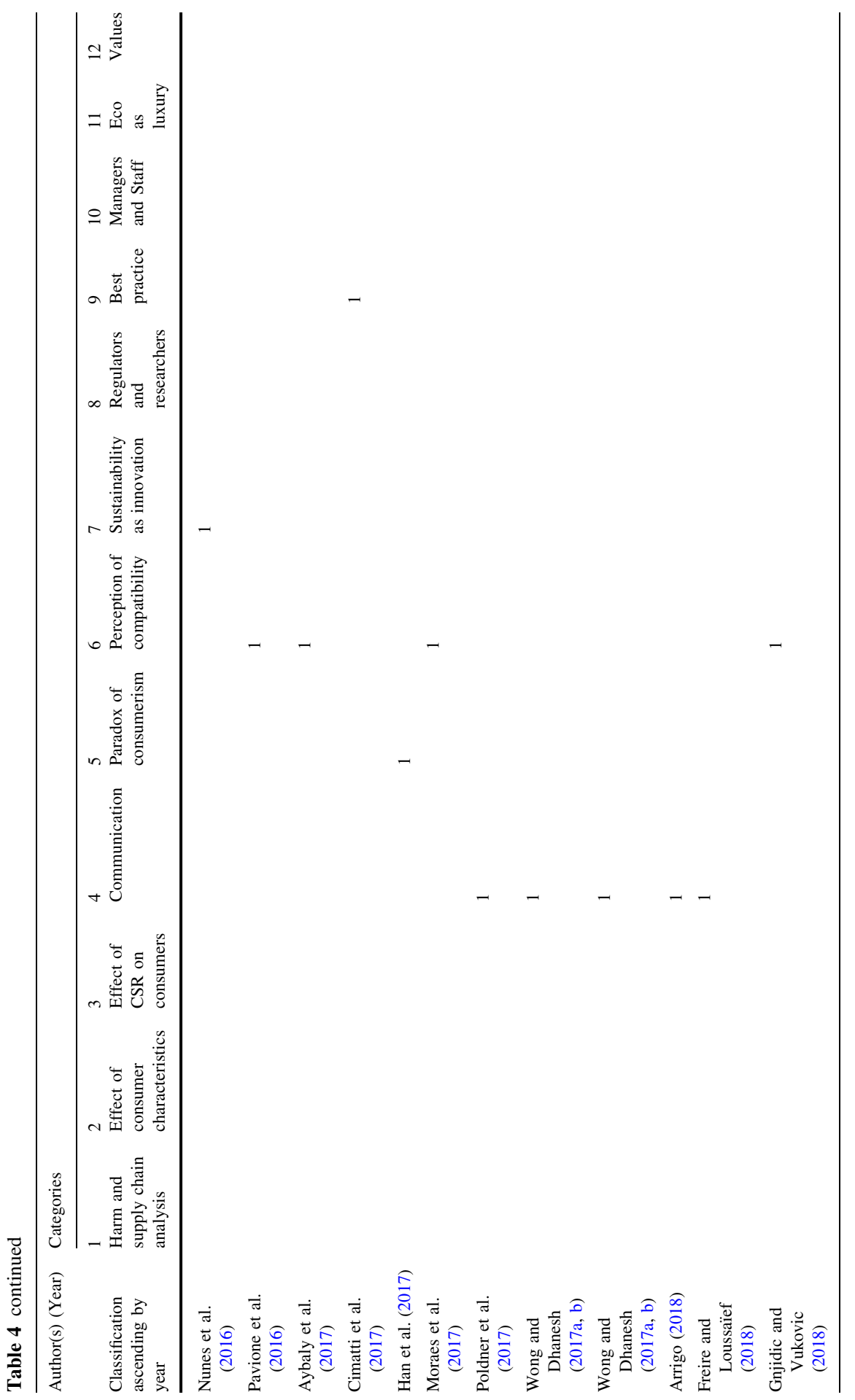

\section{글 Springer}




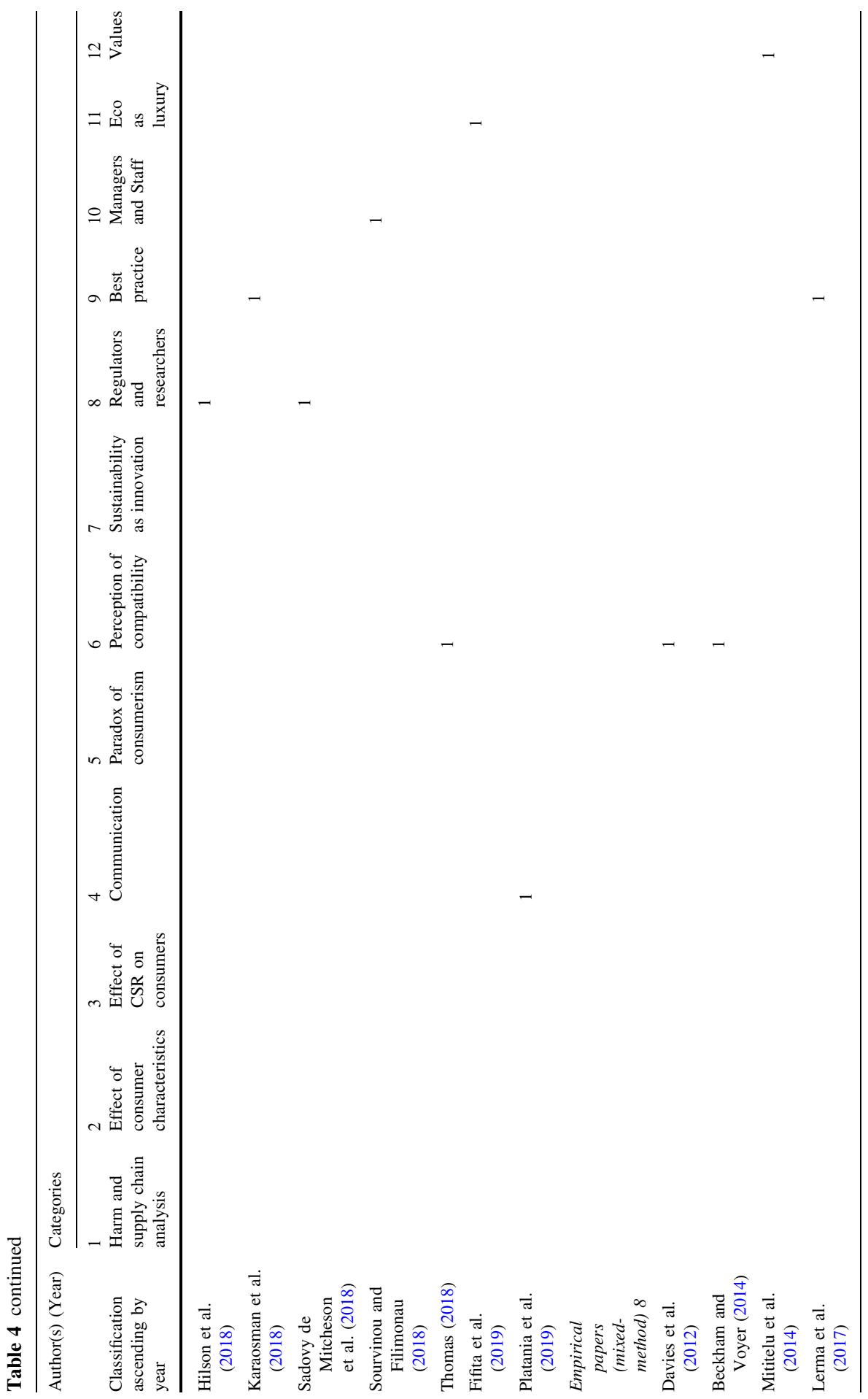




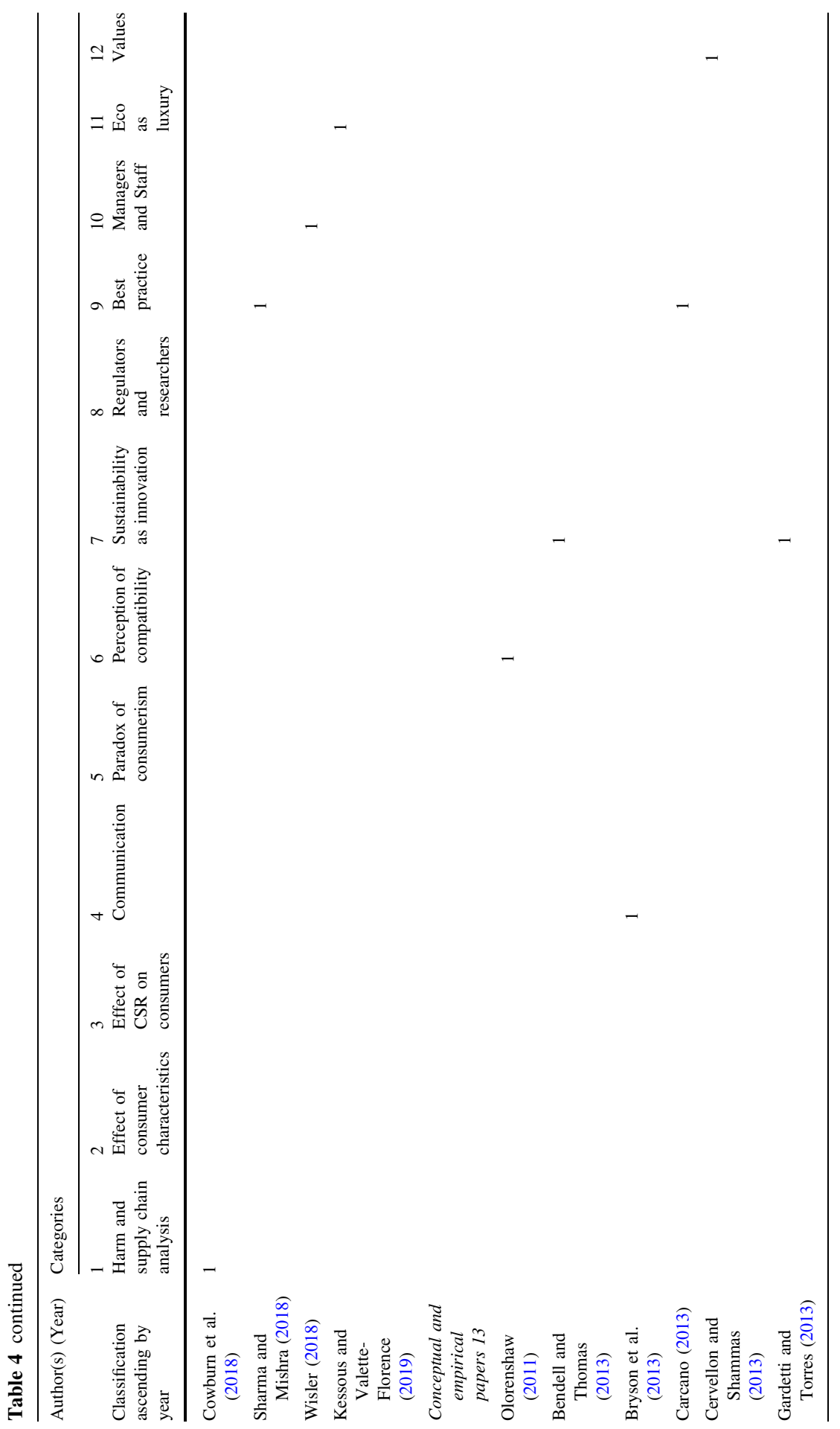




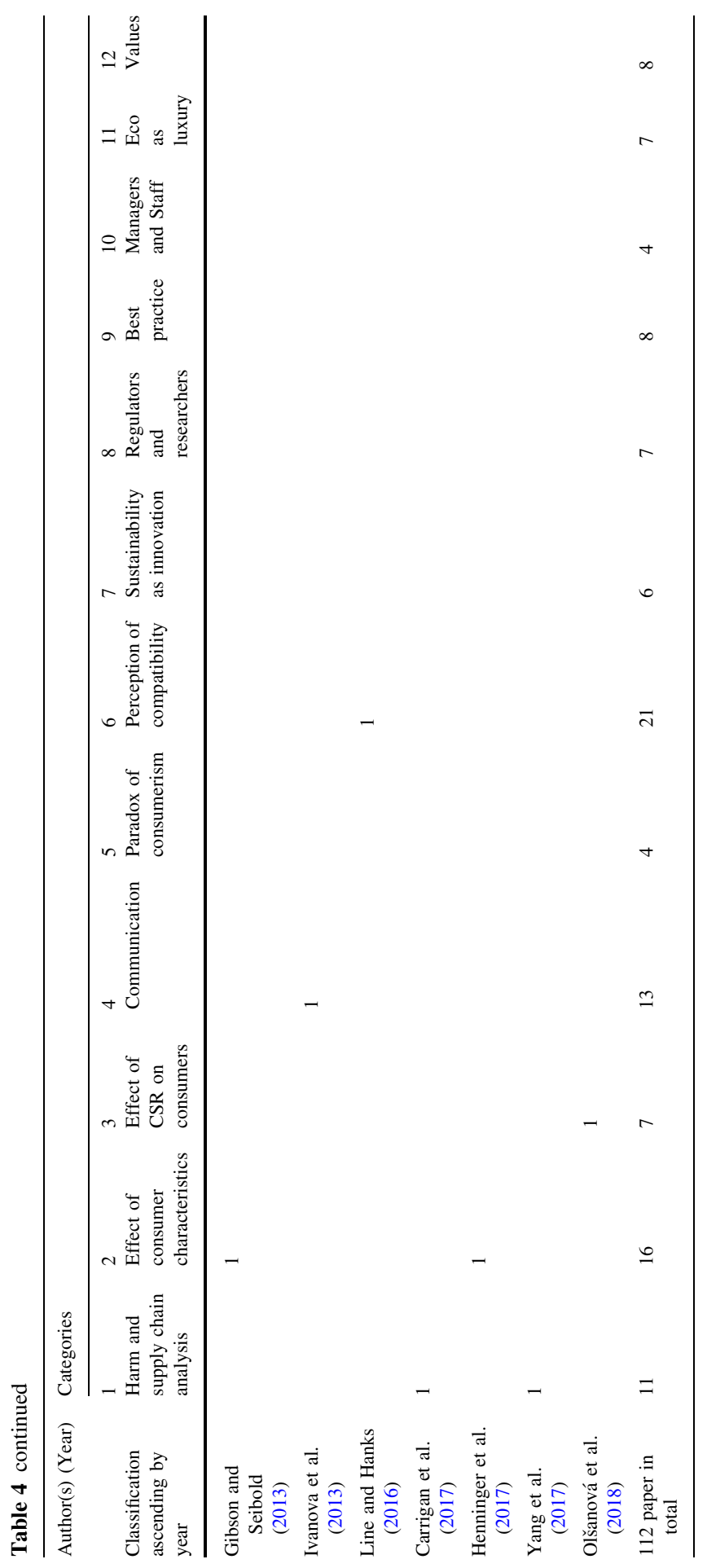




\section{References}

Achabou, M.A., and S. Dekhili. 2013. Luxury and sustainable development: Is there a match? Journal of Business Research 66 (10): 1896-1903.

Aguinis, H., and A. Glavas. 2012. What we know and don't know about Corporate Social Responsibility: A review and research agenda. Journal of Management 38: 932-968.

Aguinis, H., and A. Glavas. 2013. Embedded versus peripheral corporate social responsibility: Psychological foundations. Industrial and Organizational Psychology: Perspectives on Science and Practice 6: 1-40.

Ahn, S. 2015. The effect of luxury product pricing on consumer's perceptions about CSR activities. Academy of Marketing Studies Journal 13 (3): 1-14.

Ahn, Y.H., and A.R. Pearce. 2013. Green luxury: A case study of two green hotels. Journal of Green Building 1: 90-119.

Ali, S.H. 2017. The ecology of diamond sourcing: from mined to synthetic gems as a sustainable transition. Journal of Bioeconomics 19 (1): 115-126.

Ali, A., G. Xiaoling, A. Ali, M. Sherwani, and F.M. Muneeb. 2019. Customer motivations for sustainable consumption: Investigating the drivers of purchase behavior for a green-luxury car. Business Strategy and the Environment. 28: 833-846.

Alshehhi, A., H. Nobanee, and N. Khare. 2018. The impact of sustainability practices on corporate financial performance: Literature trends and future research potential. Sustainability 10 (2): 494.

Amaldoss, W., and S. Jain. 2002. An analysis of the impact of social factors on purchase behaviour. Review of Marketing Science Working Papers 2 (1): 1-44.

Amatulli, C., M. De Angelis, M. Costabile, and G. Guido. 2017a. Sustainable luxury brands: Evidence from research and implications for managers. London: Springer.

Amatulli, C., M. De Angelis, D. Korschun, and S. Romani. 2018. Consumers' perceptions of luxury brands' CSR initiatives: An investigation of the role of status and conspicuous consumption. Journal of Cleaner Production 194: 277-287.

Amatulli, C., M. De Angelis, G. Pino, and G. Guido. 2017b. Unsustainable luxury and negative word-ofmouth: The role of shame and consumers' cultural orientation. Advances in Consumer Research 45: 498.

Arrigo, E. 2018. The flagship stores as sustainability communication channels for luxury fashion retailers. Journal of Retailing and Consumer Services 44: 170-177.

Arrington, D.W. 2017. Ethical and sustainable luxury: The paradox of consumerism and caring. Fashion, Style and Popular Culture 4 (3): 277-285.

Athwal, N., V.K. Wells, M. Carrigan, and C.E. Henninger. 2019. Sustainable luxury marketing: A synthesis and research agenda. International Journal of Management Reviews 13: 1-22.

Aupperle, K.E. 1984. An empirical measure of corporate social orientation. Research in Corporate Social Policy and Performance 6: 27-54.

Aybaly, R., L. Guerquin-Kern, I. Coste Manière, D. Madacova, and J. van Holt. 2017. Sustainability practices in the luxury industry: How can one be sustainable in an over-consumptive environment?: Sustainability in the automotive world: The case of Tesla. Procedia Computer Science 122: 541-547.

Barakat, S.R., G. Isabella, J.M.G. Boaventura, and J.A. Mazzon. 2016. The influence of corporate social responsibility on employee satisfaction. Management Decision 54 (9): 2325-2339.

Bastien, V., and J.N. Kapferer. 2013. More on luxury anti-laws of marketing. In Luxury marketing, ed. K.P. Wiedmann and N. Hennigs, 19-34. Wiesbaden: Gabler Verlag.

Beckham, D., and B.G. Voyer. 2014. Can sustainability be luxurious? A mixed-method investigation of implicit and explicit attitudes towards sustainable luxury consumption. Advances in Consumer Research 42: 245-250.

Bendell, J., and A. Kleanthous. 2007. Deeper luxury. https://assets.wwf.org.uk/downloads/luxury_report. pdf. Accessed 20 Aug 2019.

Bendell, J., and L. Thomas. 2013. The appearance of elegant disruption: Theorising sustainable luxury entrepreneurship. Journal of Corporate Citizenship 2013 (52): 9-24.

Berger, J. 2017. Are luxury brand labels and "green" labels costly signals of social status? An extended replication. PLOS ONE 12 (2): e0170216.

Berry, C. 1994. The idea of luxury: A conceptual and historical investigation. Cambridge: Cambridge University Press. 
Berthon, P., L. Pitt, M. Parent, and J.-P. Berthon. 2009. Aesthetics and ephemerality: Observing and preserving the luxury brand. California Management Review 52: 45-66.

Blackman, A., M.A. Naranjo, J. Robalino, F. Alpízar, and J. Rivera. 2014. Does tourism eco-certification pay? Costa Rica's Blue Flag Program. World Development 45: 41-52.

Brammer, S., S. Hoejmose, and A. Millington. 2011. Managing sustainable global supply chains: A systematic review of the body of knowledge. London: Network for Business Sustainability.

Bryson, D., G. Atwal, and P. Hultén. 2013. Towards the conceptualisation of the antecedents of extreme negative affect towards luxury brands. Qualitative Market Research 16 (4): 393-405.

Carcano, L. 2013. Strategic management and sustainability in luxury companies: The IWC Case. Journal of Corporate Citizenship 2013 (52): 36-54.

Carey, L., and M.-C. Cervellon. 2014. Ethical fashion dimensions: Pictorial and auditory depictions through three cultural perspectives. Journal of Fashion Marketing and Management 18 (4): 483-506.

Carlowitz, H. C. v. 2013. Sylvicultura oeconomica. München: Oekom Verlag. (Original from 1713)

Carrigan, M., M. Mceachern, C. Moraes, and C. Bosangit. 2017. The fine jewellery industry: Corporate responsibility challenges and institutional forces facing SMEs. Journal of Business Ethics 143 (4): 681-699.

Carrigan, M., C. Moraes, and M. McEachern. 2013. From conspicuous to considered fashion: A harmchain approach to the responsibilities of luxury-fashion businesses. Journal of Marketing Management 29 (11-12): 1277-1307.

Carroll, A.B. 1979. A three-dimensional conceptual model of corporate performance. Academy of Management Review 4 (4): 497-505.

Carroll, A.B. 1991. The pyramid of corporate social responsibility: Toward the moral management of organizational stakeholders. Business Horizons 34 (4): 39-48.

Carroll, A.B. 2016. Carroll's pyramid of CSR: Taking another look. International Journal of Corporate Social Responsibility 1: 3.

Carroll, A.B., and K.M. Shabana. 2010. The business case for corporate social responsibility: A review of concepts, research and practice. International Journal of Management Reviews 12 (1): 85-105.

Cervellon, M.-C. 2013. Conspicuous conservation: Using semiotics to understand sustainable luxury. International Journal of Market Research 5: 695-717.

Cervellon, M.-C., and L. Shammas. 2013. The value of sustainable luxury in mature markets: A Customer-based approach. Journal of Corporate Citizenship 52: 90-101.

Chang, D.R., J. Jang, H. Lee, and M. Nam. 2019. The effects of power on consumers' evaluation of a luxury brand's corporate social responsibility. Psychology \& Marketing 36 (1): 72-83.

Cheah, I., Z. Zainol, and I. Phau. 2016. Conceptualizing country-of-ingredient authenticity of luxury brands. Journal of Business Research 69 (12): 5819-5826.

Chen, H., J. Zhou, and J. Yu. 2016. Consumer perception and consumption behavior regarding luxury products in the fashion industry. International Journal of Business, Marketing, \& Decision Science 9 (1): 84-96.

Cherapanukorn, V., and K. Focken. 2014. Corporate social responsibility (CSR) and sustainability in Asian luxury hotels: Policies, practices and standards. Asian Social Science 10 (8): 198-209.

Cheyne, J., and S. Barnett. 2001. The greening of accommodation: Stakeholder perspectives of environmental programmes in New Zealand hotels and luxury lodges. Journal of Corporate Citizenship 1: 115-126.

Childs, J. 2008. Reforming small scale mining in sub-Saharan Africa: Political and ideological challenges to a Fair Trade gold initiative. Resources Policy 33 (4): 203-209.

Childs, J. 2014. A new means of governing artisanal and small scale mining? Fairtrade gold and development in Tanzania. Resources Policy 40: 128-136.

Choi, T.-M. 2014. Luxury fashion branding: Literature review, research trends, and research agenda. In Fashion branding and consumer behaviors, International series on consumer science, ed. T.-M. Choi, 7-16. New York: Springer.

Cimatti, B., G. Campana, and L. Carluccio. 2017. Eco design and sustainable manufacturing in fashion: A case study in the luxury personal accessories industry. Procedia Manufacturing 8: 393-400.

Coviello, N.E., and M.V. Jones. 2004. Methodological issues in international entrepreneurship research. Journal of Business Venturing 19 (4): 485-508.

Cowburn, B., C. Moritz, C. Birrell, G. Grimsditch, and A. Abdulla. 2018. Can luxury and environmental sustainability co-exist? Assessing the environmental impact of resort tourism on coral reefs in the Maldives. Ocean and Coastal Management 158: 120-127. 
Csaba, F.F., and E. Skjold. 2018. Fur and sustainability: Oxymoron or key to 'deeper' luxury? Journal of Design, Business \& Society 4 (2): 131-149.

Dahlsrud, A. 2008. How corporate social responsibility is defined: An analysis of 37 definitions. Corporate Social Responsibility and Environmental Management 15: 1-13.

Davies, I.A., Z. Lee, and I. Ahonkhai. 2012. Do consumers care about ethical-luxury? Journal of Business Ethics 106 (1): 37-51.

De Angelis, M., F. Adıgüzel, and C. Amatulli. 2017. The role of design similarity in consumers' evaluation of new green products: An investigation of luxury fashion brands. Journal of Cleaner Production 141: 1515-1527.

De Barnier, V., I. Rodina, and P. Valette-Florence. 2006. Which luxury perceptions affect most consumer purchase behavior? A cross-cultural exploratory study in France, the United Kingdom and Russia. Working Paper. Paris: University Pierre-Mendes-France of Grenoble.

Dekhili, S., M.A. Achabou, and F. Alharbi. 2019. Could sustainability improve the promotion of luxury products? European Business Review 31 (4): 488-511.

de Klerk, H., M. Kearns, and M. Redwood. 2019. Controversial fashion, ethical concerns and environmentally significant behaviour. International Journal of Retail \& Distribution Management 47 (1): 19-38.

de Miguel Molina, B., M. de Miguel Molina, and M.E. Rumiche-Sosa. 2011. Does luxury indicate sustainability? An analysis of the Maldives. Electronic Journal of Business Ethics and Organization Studies 16 (1): 21-32.

de Miguel-Molina, B., M. de Miguel-Molina, and M.E. Rumiche-Sosa. 2014. Luxury sustainable tourism in Small Island Developing States surrounded by coral reefs. Ocean and Coastal Management 98 : 86-94.

Depeyre, C., E. Rigaud, and F. Seraidarian. 2018. Coopetition in the French luxury industry: Five cases of brand-building by suppliers of luxury brands. Journal of Brand Management 25 (5): 463-473.

DiDonato, T., and B.K. Jakubiak. 2016. Sustainable decisions signal sustainable relationships: How purchasing decisions affect perceptions and romantic attraction. Journal of Social Psychology 156 (1): $8-27$.

Dogan-Sudas, H., A. Kara, and S. Cabuk. 2019. The role of sustainable environment attributes in luxury product perceptions: Evidence from an emerging market. Journal of Transnational Management 24 (1): 3-20.

Donzé, P.Y., and B. Wubs. 2019. Storytelling and the making of a global luxury fashion brand: Christian Dior. International Journal of Fashion Studies 6 (1): 83-102.

Doval, J., P. Etinder, and G.S. Batra. 2013. Green buzz in luxury brands. Review of Management 3 (3/4): 5-14.

Dresner, S. 2008. The Principles of Sustainability. London: Earthscan.

Dubois, B., and G. Laurent. 1994. Attitudes towards the concept of luxury: An exploratory analysis. In AP - Asia Pacific advances in consumer research 1, ed. J.A. Cote and S.M. Leong, 470-477. Provo: Association for Consumer Research.

Dubois, B., G. Laurent, and S. Czellar. 2001. Consumer rapport to luxury: Analyzing complex and ambivalent attitudes. Working Paper 736. Paris: HEC School of Management. X working paper

Dubois, B., and C. Paternault. 1995. Observations: Understanding the world of international luxury brands: The "dream formula". Journal of Advertising Research 35 (4): 69-76.

Edmondson, V.C., and A.B. Carroll. 1999. Giving back: An examination of the philanthropic motivations, orientations and activities of large black-owned businesses. Journal of Business Ethics 19 (2): 171-179.

Fifita, 'I.M.E., Y. Seo, E. Ko, D. Conroy, and D. Hong. 2019. Fashioning organics: Wellbeing, sustainability, and status consumption practices. Journal of Business Research.

Fink, A. 2005. Conducting research literature reviews: From the internet to paper. Thousand Oaks: Sage Publications.

Freeman, R.E., and S.R. Velamuri. 2006. A new approach to CSR: Company stakeholder responsibility. Corporate social responsibility. London: Palgrave Macmillan.

Freire, A.N., and L. Loussaïef. 2018. When advertising highlights the binomial identity values of luxury and CSR principles: The examples of Louis Vuitton and Hermès. Corporate Social Responsibility and Environmental Management 25 (4): 565-582.

Fuerst, F., and C. Shimizu. 2016. Green luxury goods? The economics of eco-labels in the Japanese housing market. Journal of the Japanese and International Economies 39: 108-122. 
Gardetti, M.A. ed. 2017. Sustainable management of luxury. Springer book series on environmental footprints and eco-design of products and processes. Singapore: Springer.

Gardetti, M.A., and A.L. Torres. 2013. Entrepreneurship, innovation and luxury: The Aïny Savoirs Des Peuple case. Journal of Corporate Citizenship 52: 55-57.

Gatti, L., and P. Seele. 2014. Evidence for the prevalence of the sustainability concept in European corporate responsibility reporting. Sustainability Science 9 (1): 89-102.

Gibson, P., and S. Seibold. 2013. Understanding and influencing eco-luxury consumers. International Journal of Social Economics 41 (9): 780-800.

Glavič, P., and R. Lukman. 2007. Review of sustainability terms and their definitions. Journal of Cleaner Production 15 (18): 1875-1885.

Gnjidic, V., and R.K. Vukovic. 2018. Managing CSR in Croatian Hospitality: The case of luxury boutique hotels. Indian Journal of Commerce and Management Studies 9 (3): 1-8.

Gond, J.-P., A. El Akremi, V. Swaen, and N. Babu. 2017. The psychological microfoundations of corporate social responsibility: A person-centric systematic review. Journal of Organizational Behavior 38: 225-246.

Griskevicius, V., J.M. Tybur, and B.V.D. Bergh. 2010. Going green to be seen: Status, reputation, and conspicuous conservation. Journal of Personality and Social Psychology 98 (3): 392-404.

Guercini, S., and S. Ranfagni. 2013. Sustainability and luxury: The Italian case of a supply chain based on native wools. Journal of Corporate Citizenship 52: 76-89.

Han, J., Y. Seo, and E. Ko. 2017. Staging luxury experiences for understanding sustainable fashion consumption: A balance theory application. Journal of Business Research 74: 162-167.

Hartmann, L.H., S. Nitzko, and A. Spiller. 2016. The significance of definitional dimensions of luxury food. British Food Journal 118 (8): 245-250.

Hartmann, L.H., S. Nitzko, and A. Spiller. 2017. Segmentation of German consumers based on perceived dimensions of luxury food. Journal of Food Products Marketing 23 (7): 733-768.

Haunschild, R., L. Leydesdorff, L. Bornmann, I. Hellsten, and W. Marx. 2019. Does the public discuss other topics on climate change than researchers? A comparison of explorative networks based on author keywords and hashtags. Journal of Informetrics 13 (2): 695-707.

Hennigs, N., K.-P. Wiedmann, C. Klarmann, and S. Behrens. 2013. Sustainability as part of the luxury essence: Delivering value through social and environmental excellence. Journal of Corporate Citizenship 2013 (52): 25-35.

Hennigs, N., K.-P. Wiedmann, C. Klarmann, S. Strehlau, B. Godey, D. Pederzoli, A. Neulinger, K. Dave, G. Aiello, R. Donvito, K. Taro, J. Táborecká-Petrovicová, C. Rodríguez Santos, J. Jung, and H. Oh. 2012. What is the value of luxury? A cross-cultural consumer perspective. Psychology and Marketing 29 (12): 1018-1034.

Henninger, C.E., P.J. Alevizou, J.L. Tan, Q. Huang, and D. Ryding. 2017. Consumption strategies and motivations of Chinese consumers The case of UK sustainable luxury fashion. Journal of Fashion Marketing and Management 21 (3): 419-434.

Hilson, G. 2008. Fair trade gold: Antecedents, prospects and challenges. Geoforum 39 (1): 386-400.

Hilson, G., A. Gillani, and S. Kutaula. 2018. Towards sustainable pro-poor development? A critical assessment of fair trade gold. Journal of Cleaner Production 186: 894-904.

Ho, H.C., M.A. Awan, and H.U. Khan. 2016. Luxury brands and corporate social responsibility: A perspective on consumers' preferences. Journal of International Management Studies 16: 77-81.

Hsieh, H.F., and S.E. Shannon. 2005. Three approaches to qualitative content analysis. Qualitative Health Research 15 (9): 1277-1288.

Ivanova, O., K. Poldner, and O. Branzei. 2013. Touch and feel. Journal of Corporate Citizenship 2013 (52): 102-130.

Jain, S. 2019. Factors affecting sustainable luxury purchase behavior: A conceptual framework. Journal of International Consumer Marketing 31 (2): 130-146.

Janssen, C., J. Vanhamme, and S. Leblanc. 2017. Should luxury brands say it out loud? Brand conspicuousness and consumer perceptions of responsible luxury. Journal of Business Research 77: $167-174$.

Janssen, C., J. Vanhamme, A. Lindgreen, and C. Lefebvre. 2014. The catch-22 of responsible luxury: Effects of luxury product characteristics on consumers' perception of fit with corporate social responsibility. Journal of Business Ethics 119: 45-57.

Jin, Y.-J., S.-C. Park, and J.-W. Yoo. 2017. Effects of corporate social responsibility on consumer credibility perception and attitude toward luxury brands. Social Behavior and Personality: An International Journal 45 (5): 795-808. 
Johnson, C.M., A. Tariq, and T.L. Baker. 2018. From Gucci to green bags: Conspicuous consumption as a signal: For pro-social behaviour. Journal of Marketing Theory and Practice 26 (4): 339-356.

Joy, A., J. Sherry Jr., A. Venkatesh, J. Wang, and R. Chan. 2012. Fast fashion, sustainability, and the ethical appeal of luxury brands fashion theory. Journal of Dress Body and Culture 16 (3): 273-295.

Kajikawa, Y. 2008. Research core and framework of sustainability science. Sustainability Science 3 (2): 215-239.

Kale, G.Ö., and G. Öztürk. 2016. The importance of sustainability in luxury brand management. Intermedia International e-Journal 3 (4): 106-126.

Kapferer, J.-N. 1997. Managing luxury brands. Journal of Brand Management 4 (4): 251-260.

Kapferer, J.-N. 2014. The future of luxury: Challenges and opportunities. Journal of Brand Management 21 (9): 716-726.

Kapferer, J.-N., and V. Bastien. 2009. Luxury Strategy: Break the rules of marketing to build luxury. London: Kogan Page.

Kapferer, J.-N., and A. Michaut. 2015. Luxury and sustainability: A common future? The match depends on how consumers define luxury. Luxury Research Journal 1 (1): 3-17.

Kapferer, J.-N., and A. Michaut-Denizeau. 2014. Is luxury compatible with sustainability? Luxury consumers' viewpoint. Journal of Brand Management 21: 1-22.

Kapferer, J.-N., and P. Valette-Florence. 2019. How self-success drives luxury demand: An integrated model of luxury growth and country comparisons. Journal of Business Research 102: 273-287.

Karaosman, H., P. Perry, A. Brun, and G. Morales-Alonso. 2018. Behind the runway: Extending sustainability in luxury fashion supply chains. Journal of Business Research 122: 541-547.

Keith, S., and M. Silies. 2015. New life luxury: Upcycled Scottish heritage textiles International. Journal of Retail \& Distribution Management 43 (10/11): 1051-1064.

Kerr, M., J. Richard, and P. Chip. 2009. Corporate social responsibility: Alegal analysis. Ontario: LexisNexis Canada Inc.

Kessous, A., and P. Valette-Florence. 2019. "From Prada to Nada": Consumers and their luxury products: A contrast between second-hand and first-hand luxury products. Journal of Business Research 102: 313-327.

Ki, C.-W., and Y.-K. Kim. 2016. Sustainable versus conspicuous luxury fashion purchase: Applying selfdetermination theory. Family and Consumer Sciences Research Journal 44 (3): 309-323.

Koch, C., S. Bekmeier-Feuerhahn, P.M. Bögel, and U. Adam. 2019. Employees' perceived benefits from participating in CSR activities and implications for increasing employee's engagement in CSR. Corporate Communications: An International Journal 24 (2): 303-317.

Kumar, A., A. Sinha, A. Arora, and A. Aggarwal. 2018. Impact of CSR activities on the financial performance of firms. MUDRA: Journal of Finance and Accounting 5 (1): 75-89.

Lasslop, I. 2005. Identitätsorientierte Führung von Luxusmarken [Identity-based management of luxury brands]. In Markenmanagement. Grundfragen der identitätsorientierten Markenführung [Brand management: Basic questions of identity-based brand management], ed. Meffert, H. and Burmann, C. and Koers, M., 327-352. Wiesbaden: Gabler.

Lee, M.-D.P. 2008. A review of the theories of corporate social responsibility: Its evolutionary path and the road ahead. International Journal of Management Reviews 10 (1): 53-73.

Lerma, B., D. dal Palù, M.A. Grande, and C. de Giorgi. 2017. Could black be the new gold? Designdriven challenges in new sustainable luxury materials for jewellery. Sustainability 10 (1): 1-4.

Li, J., and K.K. Leonas. 2019. Trends of Sustainable Development Among Luxury Industry. In Sustainable luxury. Environmental footprints and eco-design of products and processes, ed. M. Gardetti and S. Muthu, 107-126. Singapore: Springer.

Line, N.D., and L. Hanks. 2016. The effects of environmental and luxury beliefs on intention to patronize green hotels: The moderating effect of destination image. Journal of Sustainable Tourism 24 (6): 904-925.

Lucà, F. 2014. The luxury industry in the wind of change toward sustainability building sustainable legacies. The New Frontier of Societal Value Co-Creation 2014 (4): 9-34.

Margolis, J.D., and J.P. Walsh. 2003. Misery loves companies: Rethinking social initiatives by business. Administrative Science Quarterly 48: 268-305.

Mathur, S., K. Khanna, and S.K. Saxena. 2019. Selecting sustainable luxury: An empirical study of customer's choice of hotels in Delhi. International Journal of Civil Engineering and Technology 10 (1): 1176-1185.

McKinsey. 1990. The luxury industry: An asset for France. Paris: McKinsey. 
Melo, T., R.C. Moura-Leite, and R.C. Padgett. 2012. Conceptualization of corporate social responsibility by the luxury hotels in Natal/RN, Brazil. Caderno Virtual de Turismo 12 (2): 152-166.

Miller, S.R., L. Eden, and D. Li. 2018. CSR reputation and firm performance: A dynamic approach. Journal of Business Ethics.

Mititelu, C., G. Fiorani, and S. Mariani. 2014. Cause related marketing: Armani initiative 'acqua for life'. International Review on Public and Nonprofit Marketing 11 (3): 285-305.

Moraes, C., M. Carrigan, C. Bosangit, C. Ferreira, and M. McGrath. 2017. Understanding ethical luxury consumption through practice theories: A study of fine jewellery purchases. Journal of Business Ethics 145 (3): 525-543.

Nash, J., C. Ginger, and L. Cartier. 2016. The sustainable luxury contradiction: Evidence from a consumer study of marine-cultured pearl jewellery. Journal of Corporate Citizenship 63: 73-95.

Nueno, J.L., and J.A. Quelch. 1998. The mass marketing of luxury. Business Horizons 41 (6): 61-68.

Nunes, B., D. Bennett, and D. Shaw. 2016. Green operations strategy of a luxury car manufacturer. Technology Analysis \& Strategic Management 28 (1): 24-39.

Olorenshaw, R. 2011. Luxury and the recent economic crisis. Vie \& Sciences de l'Entreprise 188: 73-90.

Olšanová, K., G. Cook, and M. Zlatic. 2018. Influence of Luxury companies' corporate social responsibility activities on consumer purchase intention: Development of a theoretical framework. Central European Business Review 7 (3): 1-25.

Orlitzky, M., F.L. Schmidt, and S.L. Rynes. 2003. Corporate social and financial performance: A metaanalysis. Organization Studies 24: 403-411.

Partridge, D.J. 2011. Activist capitalism and supply chain citizenship: Producing ethical regimes and ready-to-wear clothes. Current Anthropology 52 (3): 97-111.

Pavione, E., R. Pezzetti, and M. Dalla' Ava. 2016. Emerging competitive strategies in the global luxury industry in the perspective of sustainable development: The case of Kering Group. Management Dynamics in the Knowledge Economy 4 (2): 241-261.

Peloza, J. 2009. The challenge of measuring financial impacts from investments in corporate social performance. Journal of Management 35: 1518-1541.

Peng, N., and A. Chen. 2019. Luxury hotels going green-The antecedents and consequences of consumer hesitation. Journal of Sustainable Tourism.

Petersen, F.E., and K. Wilcox. 2016. Education, liberalism and consumers' response to luxury brands. Advances in Consumer Research 44: 589.

Pinkston, T.S., and A.B. Carroll. 1996. A retrospective examination of CSR orientations: Have they changed? Journal of Business Ethics 15 (2): 199-206.

Pinto, D.C., M. Maurer Herter, D. Gonçalves, and E. Sayin. 2019. Can luxury brands be ethical? Reducing the sophistication liability of luxury brands. Journal of Cleaner Production 233: 1366-1376.

Platania, S., G. Santisi, and M. Morando. 2019. Impact of emotion in the choice of eco-luxury brands: The multiple mediation role of the brand love and the brand trust. Quality - Access to Success 20 (S2): 501-506.

Poldner, K., D. Dentoni, and O. Ivanova. 2017. Aesthetic mediation of creativity, sustainability and the organization. Journal of Cleaner Production 140 (3): 1936-1947.

Polonsky, M.J., L. Carlson, and M.L. Fry. 2003. The harm chain: A public policy development and stakeholder perspective. Marketing Theory 3 (3): 345-364.

Rishi, M., V. Jauhari, and G. Joshi. 2015. Marketing sustainability in the luxury lodging industry: A thematic analysis of preferences amongst the Indian transition generation. Journal of Consumer Marketing 32 (5): 376-391.

Roberts, J. 2019. Luxury international business: A critical review and agenda for research. Critical Perspectives on International Business 15 (2/3): 219-238.

Rolling, V., and A. Sadachar. 2018. Are sustainable luxury goods a paradox for millennials? Social Responsibility Journal 14 (4): 802-815.

Rosenbaum, M.S. 2015. Green marketing programs as strategic initiatives in hospitality. The Journal of Services Marketing 29 (2): 81-92.

Rupp, D.E., and D.B. Mallory. 2015. Corporate social responsibility: Psychological, person-centric, and progressing. Annual Review of Organizational Psychology and Organizational Behavior 2 (1): 211-236.

Ryan, C., and M. Stewart. 2009. Eco-tourism and luxury-The case of Al Maha. Dubai Journal of Sustainable Tourism 17 (3): 287-301. 
Sadovy de Mitcheson, Y., A.A. Andersson, A. Hofford, C.S.W. Law, L.C.Y. Hau, and D. Pauly. 2018. Out of control means off the menu: The case for ceasing consumption of luxury products from highly vulnerable species when international trade cannot be adequately controlled; shark fin as a case study. Marine Policy 98: 115-120.

Schwartz, S.H. 1992. Universals in the content and structure of values: Theoretical advances and empirical tests in 20 countries. In Advances in experimental social psychology, vol. 25, ed. M.P. Zanna, 1-65. San Diego: Academic Press.

Schwartz, M., and A. Carroll. 2003. Corporate social responsibility: A three-domain approach. Business Ethics Quarterly 13 (4): 503-530.

Sharma, S., and P. Mishra. 2018. Impact of corporate social responsibility practices on the corporate performance of luxury chain hotels. Journal of Services Research 18 (1): 47-57.

Shilpa, V., and C. Madhavaiah. 2017. Luxury fashion goods and sustainable consumption behaviour. Journal of Marketing Vistas 7 (2): 60-66.

Shim, C., S. Kang, I. Kim, and S.S. Hyun. 2017. Luxury-cruise travellers' brand community perception and its consequences. Current Issues in Tourism 20 (14): 1489-1509.

Sombart, W. 1922/1967. Liebe, Luxus und Kapitalismus: Über die Entstehung der modernen Welt aus dem Geist der Verschwendung [Love, luxury and capitalisms: About the formation of the modern world out of wastefulness]. München: Deutscher Taschenbuch Verlag.

Sourvinou, A., and V. Filimonau. 2018. Planning for an environmental management programme in a luxury hotel and its perceived impact on staff: An exploratory case study. Journal of Sustainable Tourism 26 (4): 649-667.

Steinhart, Y., O. Ayalon, and H. Puterman. 2013. The effect of an environmental claim on consumers' perceptions about luxury and utilitarian products. Journal of Cleaner Production 53: 277-286.

Stewart, H.L. 1918. The ethics of luxury and leisure. American Journal of Sociology 24 (3): 241-259.

Sthapit, A., G.-Y. Jo, and Y.-Y. Hwang. 2017. Communicating responsible luxury brand: The role of luxury-CSR fit and dispositional consensus on brand evaluation. Journal of Distribution Science 15 (2): 7-14.

Supanti, D., K. Butcher, and L. Fredline. 2015. Enhancing the employer-employee relationship through corporate social responsibility (CSR) engagement. International Journal of Contemporary Hospitality Management 27 (7): 1479-1498.

Swanson, L.A., and D.D. Zhang. 2012. Perspectives on corporate responsibility and sustainable development. Management of Environmental Quality 23 (6): 630-639.

Tascioglu, M., J.K. Eastman, and R. Iyer. 2017. The impact of the motivation for status on consumers' perceptions of retailer sustainability: The moderating impact of collectivism and materialism. The Journal of Consumer Marketing 34 (4): 292-305.

Thomas, S. 2018. Peace of mind: The quintessential luxury. Journal of Design, Business \& Society 4 (2): $151-169$.

Thomas, A.K., and P.S. James. 2012. An empirical case study on successful luxury resorts. Asia Pacific Journal of Management \& Entrepreneurship Research 1 (3): 332-348.

Tidwell, P., and B. Dubois. 1996. A cross-cultural comparison of attitudes toward the luxury concept in Australia and France. In AP - Asia pacific advances in consumer research 2, ed. B. Russel and R. Groves, 31-35. Provo: Association for Consumer Research.

Tomkins, S., S. Isley, B. London, and L. Getoor. 2018. Sustainability at scale: towards bridging the intention-behavior gap with sustainable recommendations. In Proceedings of the 12th ACM conference on recommender systems: 214-218.

Torelli, C.J., A.B. Monga, and A.M. Kaikati. 2012. Doing poorly by doing good: Corporate social responsibility and brand concepts. Journal of Consumer Research 38 (5): 948.

Towers, N., P. Perry, and R. Chen. 2013. Corporate social responsibility in luxury manufacturer supply chains: An exploratory investigation of a Scottish cashmere garment manufacturer. International Journal of Retail \& Distribution Management 41 (11/12): 961-972.

Tranfield, D., D. Denyer, and P. Smart. 2003. Towards a methodology for developing evidence-informed management knowledge by means of systematic review. British Journal of Management 14: 207-222.

Tsai, S.-P. 2005. Impact of personal orientation on luxury-brand purchase value: An International Investigation. International Journal of Market Research 47 (4): 427-452.

Turunen, L.L.M., and H. Leipämaa-Leskinen. 2015. Pre-loved luxury: Identifying the meaning of second hand luxury possessions. The Journal of Product and Brand Management 24 (1): 57-65. 
Valtin, A. 2005. Der Wert von Luxusmarken. Determinanten des konsumentenorientierten Markenwerts und Implikationen für das Luxusmarkenmanagement [The value of luxury brands. Determinants of the consumer based market value and implications for the management of luxury brands], Dissertation Universität Mannheim. Wiesbaden: Deutscher Universitäts-Verlag.

Vermeir, I., and W. Verbeke. 2006. Sustainable food consumption: Exploring the consumer "attitudebehavioral intention" gap. Journal of Agricultural and Environmental ethics 19 (2): 169-194.

Vickers, J.S., and F. Renand. 2003. The marketing of luxury goods: An exploratory study-Three conceptual dimensions. The Marketing Review 3 (4): 459-478.

Visser, M., J. Schoormans, and J. Vogtländer. 2018. Consumer buying behaviour of sustainable vacuum cleaners-Consequences for design and marketing. Journal of Cleaner Production 195: 664-673.

Waddock, S.A. 2004. Parallel universes: Companies, academics, and the progress of corporate citizenship. Business and Society Review 109: 5-42.

Wang, L., and R.S. Snell. 2013. A case study of ethical issue at Gucci in Shenzhen, China. Asian Journal of Business Ethics 2 (2): 173-183.

WBCSD. 2000. Corporate social responsibility: making good business sense. World Business Council for Sustainable Development. ISBN 2-94-024007-8

Webster, J., and R.T. Watson. 2002. Analysing the past to prepare for the future: Writing a literature review. MIS Quarterly 26 (2): xiii-xxiii.

Wiedmann, K.-P., N. Hennigs, and A. Siebels. 2007. Measuring consumers' luxury value perception: A cross-cultural framework. Academy of Marketing Science Review 7: 1-21.

Wisler, J.C. 2018. U.S. CEOs of SBUs in luxury goods organizations: A mixed methods comparison of ethical decision-making profiles. Journal of Business Ethics 149 (2): 443-518.

Wong, J.Y., and G.S. Dhanesh. 2017a. Communicating corporate social responsibility (CSR) in the luxury industry: Managing CSR-luxury paradox online through acceptance strategies of coexistence and convergence. Management Communication Quarterly 31 (1): 88-112.

Wong, J.Y., and G.S. Dhanesh. 2017b. Corporate social responsibility (CSR) for ethical corporate identity management. Corporate Communications 22 (4): 420-439.

Wong, A., and J. Zaichkowsky. 1999. Understanding luxury brands in Hong Kong. In European advances in consumer research 4, ed. B. Dubois, T.M. Lowrey, L.J. Shrum, and M. Vanhuele, 310-316. Provo: Association for Consumer Research.

Wood, D.J. 2010. Measuring corporate social performance: A review. International Journal of Management Reviews 12: 50-84.

Woodside, A.G., and M.B. Fine. 2019. Sustainable fashion themes in luxury brand storytelling: The sustainability fashion research grid. Journal of Global Fashion Marketing 10 (2): 111-128.

World Commission on Environmental Development. 1987. Our common future. Oxford: Oxford University Press.

Yang, Y., H. Han, and P.K.C. Lee. 2017. An exploratory study of the mechanism of sustainable value creation in the luxury fashion industry. Sustainability 9: 483.

Zhang, L., W. Yang, and X. Zheng. 2018. Corporate social responsibility: The effect of need-for-status and fluency on consumers' attitudes. International Journal of Contemporary Hospitality Management 30 (3): 1492-1507.

Publisher's Note Springer Nature remains neutral with regard to jurisdictional claims in published maps and institutional affiliations. 